University of Rhode Island

DigitalCommons@URI

Open Access Master's Theses

1987

\title{
The Application of Survey Research in the Community Development Planning Process
}

Louis A. Mercuri

University of Rhode Island

Follow this and additional works at: https://digitalcommons.uri.edu/theses

\section{Recommended Citation}

Mercuri, Louis A., "The Application of Survey Research in the Community Development Planning Process" (1987). Open Access Master's Theses. Paper 669.

https://digitalcommons.uri.edu/theses/669

This Thesis is brought to you for free and open access by DigitalCommons@URI. It has been accepted for inclusion in Open Access Master's Theses by an authorized administrator of DigitalCommons@URI. For more information, please contact digitalcommons-group@uri.edu. 
THE APPLICATION OF SURVEY RESEARCH

IN THE COMMUNITY DEVELOPMENT

PLANNING PROCESS

BY

LOUIS A. MERCURI

\begin{abstract}
A RESEARCH PROJECT SUBMITTED IN
PARTIAL FULFILLMENT OF THE REQUIREMENTS

FOR THE DEGREE AND MASTER OF

COMMUNITY PLANNING
\end{abstract}

UNIVERSITY OF RHODE ISLAND

1987 
MASTER OF COMMUNITY PLANNING

RESEARCH PROJECT

OF

LOUIS A. MERCURY

Approved:

Major Professor tale H. Face h.

Howard H. Foster, Jr.

Acknowledged:

Director

Hue H. Fath $h$.

Howard H. Foster, Jr. 
This work focuses on the applicability of survey research and design in the community development planning process. Compared to other similar social science fields, planning has not fully utilized surveys in a way that will keep pace with the expansion of information-based technologies. Community development planning, a major functional area in the field of planning, serves as the test for establishing the validity of this methodology. The town of Stoneham, Massachusetts (population 22,000), where the author is the community development coordinator, is used in the design, preparation, and administration of the survey. This survey was administered during the Spring of 1987 to individuals of every significant group concerned with downtown issues at that time. Based on the results of this effort, the community development survey is a valuable tool in examining every stage of the planning process, from an analysis of existing conditions to the evaluation of implemented objectives. This work investigates the design and development of the survey in terms that will be beneficial to planners. Beyond this, the role of the survey and its applicability to both process and functional area is also carefully considered. 


\section{ACKNOWLEDGMENT}

Three particular words of thanks are in order. First, for Dr. Howard Foster, Director of Community Planning at URI, for being patient and having confidence in my ability to complete this project. This work is long overdue.

Second, for Stoneham Town Administrator William Sequino, Jr., who provided me with the unique opportunity in stoneham to further develop my career in the planning profession. The challenges that we face every day in stoneham are the result of Bill's leadership and his desire to make the town a better place for its residents.

Finally, to my wife Becky, for her encouragement in helping me to bring this project to its completion. Her long hours of typing and assistance in a variety of other ways have been very special to me. Without her meaningful and caring support, this effort may never have reached completion. 


\section{PREFACE}

This work seeks to accomplish two primary objectives as a study of the survey process in community development planning. First, the practical application of the methodology suggested for use in survey design and development will prove to be a most valuable guide for the planner. Second, the framework for the application of the survey methodology in the planning context is examined.

The question of how to design a survey will be a difficult one without careful analysis of several considerations. The town of Stoneham, Massachusetts has community development problems not unlike those of many older downtowns in need of a rebirth. Parking, lack of a quality retail $\mathrm{mix}$, and loss of identity are some long-term problems that have existed and cannot be solved overnight. This test case provides the basis for the administration of the community development survey. A detailed analysis of the happenings that led to the problems, the importance of the survey in addressing the issues, the design of the survey, and the administration of the survey are studied in the 
first four sections of this project.

The last sections of this work provide the framework for the application of the survey methodology in similar planning contexts. Here, a case for the validity of the methodology, starting from a study of existing conditions to an evaluation of implemented objectives, is demonstrated. It is the theory of this author that planners and planning theoreticians have underestimated the use of surveys in the field. Possibly, the detailed study of this methodology could be conducted at the graduate school level, to better prepare the planner for the use of surveys in the actual planning environment. In this age of the proliferation of information, the ability to quantify attitudes, perceptions, and knowledge will lead to planners being better qualified to use the information obtained from surveys.

My interest in survey design and development stems from the considerable work I have done for a research polling company in Boston, Massachusetts. The difficulties involved in this work are immense when one considers that election predictions and forecasts are constantly on the line. Yet, the data obtained through polling or surveys can be extremely valuable to the future resolution of problems, or as a measurement of 
the public need. The application of survey methodology from other fields, such as political science or marketing, to planning is therefore a natural one. Beyond this, the use of surveys in the planning context broadens the means for public participation on a variety of issues.

It is my expectation that the use of surveys will become an increasingly valuable tool for planners. However, the literature must give the planner confidence and provide a solid foundation for his or her use of surveys. The author will consider this work a special success if the validity of this methodology becomes well established in the coming years, by both theoreticians and practitioners. 
TABLE OF CONTENTS

ABSTRACT ..............................

ACKNOWLEDGMENT ............................. . . i i

PREFACE................................

CHAPTER

I. STONEHAM SQUARE - NARRATIVE DESCRIPTION

AND EXISTING CONDITIONS....................

I I. DETERMINATION OF THE KEY PLANNING ISSUES

AND THEIR SIGNIFICANCE.................... 8

I I . METHODOLOGY OF SURVEY ADMINISTRATION............2I

Determination of Need for Survey Design.......21 Methodology of Survey Development

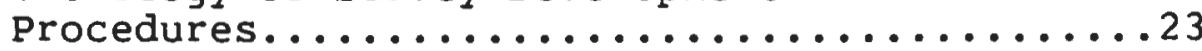

Establishment of Goals and Purpose........25

Specific Definition of the Target

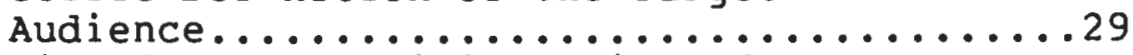

Medium for the Administration of

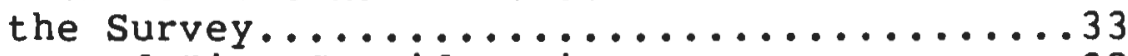

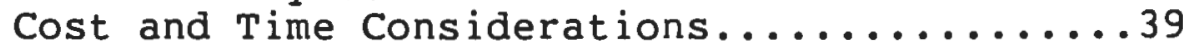

Design of the Questionnaire.............40

Editing, Coding, and Data

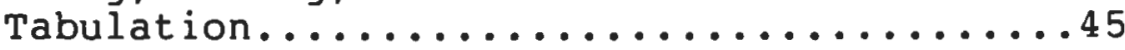

Analyze and Interpret Findings..........46

Distribution of survey Results...........46

Use of Information in Formulating

Goals and Policies..................48

Use of Future Surveys..................48

Summary of Survey Methodology...............50

IV. SURVEY RESULTS AND POLICY ALTERNATIVES.........51

Policy Alternatives......................56

V. ANALYSIS OF SURVEY RESULTS LEADING TO

POLICY FORMULATION......................6I

Use of Data.......................6l

Analysis of Information.................65 
Converting Results to Goals and Policy

Statements.......................66

Developing Goals and Priorities Through

Community Participation..............68

VI. EVALUATION OF SURVEY METHODOLOGY............73

Comparisons to Existing Literature...........73

Practicality of Surveys in the

Community Development Context............76

Overall Survey Function in Planning..........80

VII. CONCLUSIONS ON THE VALIDITY OF SURVEY

METHODOLOGY......................... 82

Need for Continuation of the Survey

Process...........................82

Purposes of Survey Development...........84

Conclusion on the validity of the

Survey Process....................86

APPENDIX

1986 Stoneham Community Development Survey......89

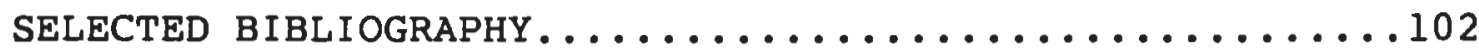




\section{LIST OF TABLES}

1. Businesses by Type in Stoneham Square as of January $1,1987 \ldots \ldots \ldots \ldots \ldots \ldots \ldots \ldots \ldots \ldots \ldots \ldots . \ldots \ldots$

2. Breakdown of Distribution of Stoneham Community Development Survey by

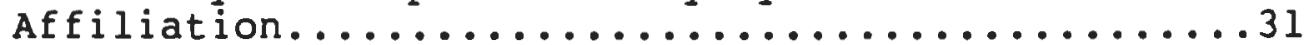

3. Comparison of Interview Methods for

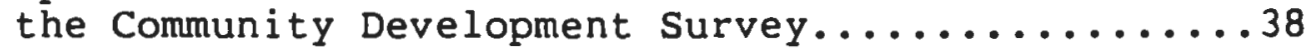

4. Questions by Survey Type.....................42

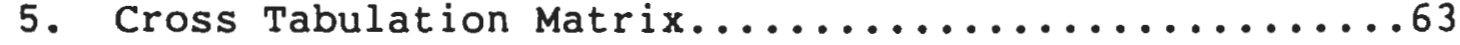




\section{EXHIBIT}

I Memo to Survey Participants.................. 52

II A Summary of Significant survey Findings........53

II Final Distribution of Survey by Affiliation......55

MAP

1. Stoneham Square: Commercial Property in

Need of Exterior Rehabilitation.............4 


\section{STONEHAM SQUARE - NARRATIVE DESCRIPTION AND EXISTING CONDITIONS}

Stoneham's older residential neighborhoods focus on the town's traditional center, Stoneham Square. During the nineteenth century, the square was the center of a thriving local shoe industry. Over the years, the decline of this shoe industry has meant a movement away from industry to a part neighborhood and part community shopping district. As with many older New England town centers, the Square has not fared well in the competition with newer retail centers and malls.

At this time, Stoneham Square is used for three primary purposes:

1. It serves as a small scale convenience retail center for local residents. Of the 88 businesses that exist in the Square, the vast majority have less than 1000 square feet available for retail or office purposes. Retail and office development is far less intensive on the upper floors of the existing structures. 
2. The Square serves as a transportation crossing point for traffic headed in every direction. Route 28 , or Main Street, bisects the Square and must be used by vehicle traffic as the north-south connection between Reading to the north and Medford to the south. The east-west connection, or Franklin Street and Montvale Avenue, helps provide access to Route 93 which carries the largest capacity of any roadway in Massachusetts or perhaps New England. Route 93 runs approximately parallel with Route 28 and is only $11 / 2$ miles east of Stoneham Square.

3. The area in and around Stoneham Square provides all general community services within a $3 / 8$ mile radius of the center of the square. The Town Hall offices, the Department of Public Works building, Public Library, Police Station, and Fire Station are all within very close proximity of the Square. Further, the three principal banks and the U.S. Post office are also located nearby.

From this description it appears that the downtown could function in a very satisfactory manner. The three traditional components of an older downtown are in place - a retail and office center, a transportation nexus, and the availability of basic 
community services. However, the transfer of shopping centers from older downtowns to neighboring malls located proximate to major highways has helped bring with it the decline that is evidenced in Stoneham Square.

When viewing Stoneham Square, a number of difficulties are immediately apparent:

1. The Square has a generally poor business mix, an extreme version of a pattern typically found in smaller downtowns. Turnover is high, particularly in the smallest retail locations.

2. The Square has a severe problem related to aesthetics and theme. Inappropriate, and often poorly maintained facades and signs, with origins from the 1950's through the 1980's, present a disjointed and run-down image. Still, these structures built in the late 1800's are architecturally sound and pose interesting renovation problems and solutions. (See Map 1)

3. The boundaries of the "downtown" area are vague, given the substantial level of commercial development along Main Street, both immediately adjacent to the Square, and for long stretches beyond the center. 
MAP 1

STONEHAM SQUARE: COMMERCIAL PROPERTY IN

NEED OF EXTERIOR REHABILITATION

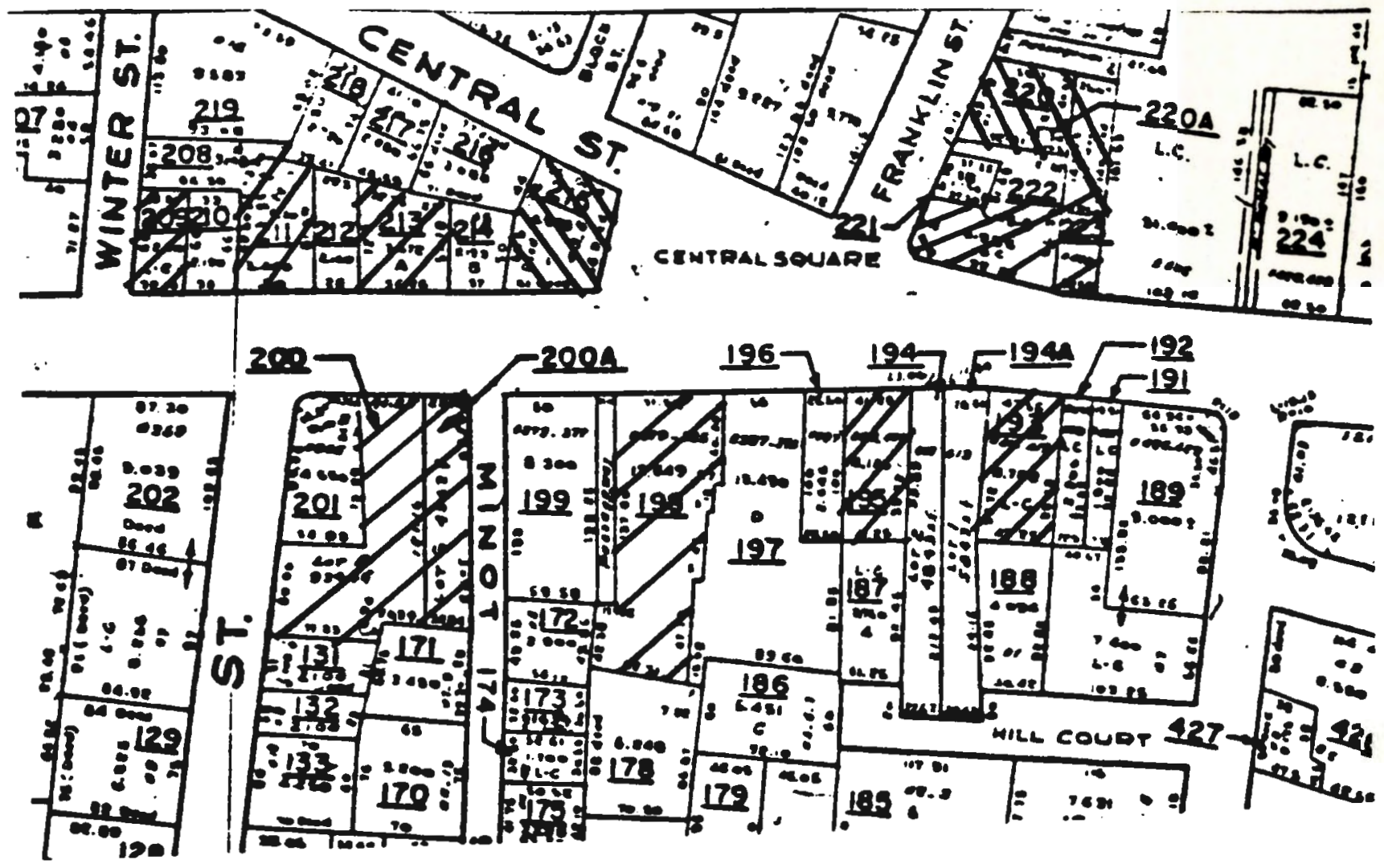

17 PROPERTIES IN NEED OF EXTERIOR 
4. The lack of substantial amounts of both on and of $f$ street parking along Main street. The importance of this issue in maintaining a viable downtown was addressed by the consultant Connery Associates in their comprehensive report to the town in January, 1986 .

Meeting each of these difficulties is not a particularly new or sudden concern. Over the years, various town officials, groups, organizations, and property owners have attempted in whole or in part to correct the deteriorating situation. Virtually every attempt has failed. If future attempts fail or a "do nothing" policy is adopted, then the character of Stoneham Square can be expected to physically deteriorate in the short term and witness a decline in the number of retail uses. In the long term, it can be expected that Stoneham square will be less of a traditional town center and more of a general purpose or office node.

A summary of the existing business type and use follows in Table 1. As of January 1, 1987 there were approximately 88 businesses in the designated Commercial Area Revitalization District (CARD), most at ground level. They are contained in 42 separate structures, with 79 individual storefronts or facades. 
Table 1

Businesses by Type in Stoneham square

as of January 1,1987

Food Market

Convenience Food

Hardware

Drugs

Auto Related

Books

General Merchandise

Jewelry

Office Supply

Hair Styling/Barber

Legal

Service Stations

Income Tax

Realtors

Restaurants/Coffee

Repair and Service

Shoe Repair

Coin Collecting

Liquor Sales

Billiards

Pet shop

Deli

Housewares

Caterer
0

1

1

1

3

0

0

2

0

8

3

1

1

2

8

4

1

1

2

1

1

1

2

1
Video/sound

Optical Center 1

Photography

3

Paint Supplies $\quad 1$

Laundromat

1

Laundry/Dry Cleaners 2

Furniture

2

Children's Clothing I

Tailors

3

Sporting Goods

1

Gift/Cards

0

Printers/Xerox 1

Medical 1

Banks 3

Health/Fitness 1

Travel Agency 1

Insurance $\quad 4$

Bars 0

Tanning Salons 2

Karate Studio 1

Florist 2

Bakery 1

Bicycles 1

$\begin{array}{ll}\text { Vacant/other } & 8\end{array}$ 
This survey was completed in January, 1987 and includes all retail businesses at street level along Main Street from Maple Street to Montvale Avenue, which stretches for about one half mile. Many of these businesses utilize extremely small quarters and therefore require very low rent levels. At this time, $63 \%$ of those using the downtown come from Stoneham, according to the "Stoneham Square Parking Study" developed from a survey by Connery Associates for the town. The downtown operates as a convenience oriented shopping center with Stoneham being the primary market area. 


\section{I. DETERMINATION OF THE KEY PLANNING ISSUES AND THEIR SIGNIFICANCE}

The lack of a revitalized downtown is an issue that is reflected in the attitude of Stoneham residents towards their community. A town of 21,424 according to the 1980 U.S. Census, Stoneham bears many similarities to the 7 cities and towns that touch its borders. The neighboring communities of Wakefield, Melrose, Reading, and Winchester are also suburban "bedroom" communities with similar populations to that of Stoneham. Each of these communities share Route 93 as the main connection to Boston only 8 miles to the south. All have smaller downtowns typical of communities that were built up during the $1800^{\prime}$ 's at the height of the shoe industry in Massachusetts.

However, Stoneham does not compare so favorably with its neighbors with respect to keeping up its downtown. Neighboring communities have used Community Development Block Grant (CDBG) funds to revitalize their downtowns. Neighborhood and business organizations have made the strengthening of downtown Melrose, winchester, and Wakefield a top priority. 
Associated with these improvements have been dramatic increases in the property values of downtown buildings and nearby housing.

In the areas of downtown revitalization and community development, Stoneham has lagged behind. Without any intervention by local government, Stoneham center would certainly continue to deteriorate and decline both physically and economically. This trend would help explain the attitude of the residents toward their elected and appointed town officials. Since the downtown serves as both a small retail center and community activities center, it is easy to see that residents would develop distrust, apathy and non-involvement in their town. Lack of participation at town meetings, low local election voter turnout, and difficulty in filling town boards and committees are sure signs of this decline. This pattern is continued when residents avoid the downtown and prefer to shop in neighboring competing malls. Without sufficient downtown business growth, commercial property owners are less likely to improve their buildings and will leave them in disrepair. This vicious cycle will continue until there is some assistance by the local government to help remedy the downtown problems. At this time, Stoneham town officials are working towards this goal. 
At the same time, it is necessary to understand some of the history of these persistent problems. The following summary highlights the difficulties leading to the existing conditions.

1. The town lacked the technical staff expertise and personnel necessary to follow through on grant applications and their implementation where applicable. Until 1981, the town was directed by the Board of Selectmen without an administrator or manager who could oversee the day-to-day community revitalization effort.

2. The lack of any significant overall zoning changes since the 1950's has meant a hodge-podge of rezoning articles that have passed Town Meeting since that time. In 1985, the Planning Board obtained State funds for a professional planning consultant to recodify and finally bring up to date a poorly thought out zoning bylaw. However, 30 years of unplanned development led to many of the disorienting land uses found near the downtown.

3. The town has never had a planner, and even now operates with only a part time clerk to serve the Planning Board. For a community in a large metropolitan area with a population of 21,000 to be without a planner in the 1980's is unusual. 
4. The presence of several community development coordinators since 1981 has made a positive difference, in that applications for state grant funding can now be undertaken. However, the lack of continuity between the ideas of each coordinator has meant incomplete and indecisive actions when some form of follow-through was necessary.

5. In reviewing previous records, at no time have town officials attempted to survey those involved with downtown activities. The survey being undertaken in this study is the first real attempt to correct the gap between the perceived needs of the public and those of town officials. The importance of keeping these lines of communication open must be a prerequisite of any community development action.

These five problem areas relate directly to the lack of action that the town and its officials have followed. Without question, much of the blame for the gradual deterioration of downtown Stoneham rests in the town's hands. However, the lack of coordination and cooperation between forces in the private and non-profit sectors have also contributed to the problem. Based on the observations and recollections of private citizens and town officials, the following conclusions can be drawn: 
1. The attitude of commercial property owners concerning building upkeep in the Square has been uninspiring at best. A pervasive attitude exists in that by improving one's own property, an adjacent property is benefited without having undertaken anything. This problem seems to stem from long-standing distrusts and dislikes between these property owners.

2. Until 1984, Stoneham existed without a local Chamber of Commerce, and in fact was under the wing of the much larger neighboring Woburn Chamber of Commerce. Since 1984, this newly formed organization has taken a very active role in the revitalization of the Square. For instance, in May 1986, the Chamber sponsored an all-day representative forum with invited speakers on the issues and problems facing the downtown. Prior to 1984, no business group could actively unite to reach a consensus on what was needed to rebuild the Square.

3. The three local banks had not made any particular financial commitments to the square. In anticipation of efforts to improve the downtown, the banks could make lower than prime rate interest loans available to property owners for property 
restoration. It is possible that more vigorous attempts by town officials to secure Community Development Block Grants would have made a significant difference in this attitude.

4. The Stoneham Square Development Corporation, a collection of public and private individuals concerned with improvements to the Square, had been essentially dormant for years. Without a staff of serious technical planning expertise, it proves impossible to bring forward a workable redevelopment plan to town officials. The concept of a marketing scheme for Stoneham Square has been beyond their capability, as the group is an all-volunteer organization with limited budget capacity. Its activities have been limited to the set-up and installation of lights and decorations in the Square during the Christmas holiday season.

5. Anxiety over the lack of parking in Stoneham Square has breeded uncertainty among property owners to develop or expand their businesses. This problem has existed ever since trolley cars disappeared form the downtown in the early 1900's. Many property owners have perceived the problem as being the result of uncooperative neighboring merchants and owners who utilize prime spaces for all-day 
parking. Once again it is the "we first" attitude that discourages anyone from making the first move to upgrade their own property. Thus it is clear that this lack of consideration for those with similar problems greatly limits what can be accomplished collectively.

From what has been described, it might appear that an entire downtown revitalization effort would be doomed to failure. The scenario being painted for Stoneham is very typical of what occurs in older, smaller cities and towns in the eastern United States. To a greater or lesser extent this also occurs in commercial retail centers located in large city neighborhoods. Community development efforts involve a large diversity of ideas, actors, priorities, and objectives. (1) When both public and private attempts fail, a downtown is faced with imminent decline and collapse. This "do nothing" scenario will leave a community center behind its neighbors and assist in the overall fall of the downtown. These patterns are exacerbated during nationally unhealthy economic climates that produce disincentives for businesses to expand, develop, and prosper.

(1) Emanuel Berk, Downtown Improvement Manual, (Chicago: American Planning Association, 1981), p. 2-1. 
The scope of this study partly involves the examination of existing problems and determining what can be done about them. By using Stoneham Square and the actors that help shape its direction, it is possible to conduct a community development survey to highlight and focus on those needs. By using Stoneham as a test case, it will be shown that surveys can be an extremely valuable tool for community development or economic development planners when establishing priorities.

Most of the issues being handled by the Stoneham Community Development office are based on general perceptions of what the problems are and are not. Unfortunately, these perceptions may not always be consistent with the actual needs of the constituents being served. Prior to the distribution of the survey, it is worthwhile to examine the most visible and prominent issues facing Stoneham Square in 1987.

At this time it appears the following areas are most critical and in need of attention:

1. The immediate need for both increased on and off street parking 
2. An improvement in the physical appearance of the commercial properties. This would include an upgrading of signs, facades, and general property maintenance and upkeep

3. The importance of attracting commercial enterprises that will make for a better retail mix downtown

4. Providing physical amenities through a downtown or an entire Route 28 beautification program. This would include the installation of benches, planters for flowers, and shrubs at specific strategic locations

5. Providing for improved relations between town officials and property owners or merchants. This could be achieved by opening the channels of communication through the community development survey

6. Attempting to improve the image of the Square as a desirable place through promotional ideas and the development of a central theme or logo

Each of these objectives has either one or several means of obtaining them. The survey provides the opportunity to both evaluate these needs and at the same time allow input that will be useful in reaching a consensus solution to the problems. 
Of equal or greater importance to this process is the newly found ability to prioritize tasks for the community development coordinator and staff. It would be an impossible task for the town and its Community Development office to completely resolve all six issues. This can be explained in two ways: first, unlimited resources of time and staff expertise do not exist, and second, many other factors beyond the community development coordinator's control can interfere with these efforts. For instance, a national economic regression would most certainly result in an erosion of business and opportunities in the downtown.

With a large assortment of measures available to deal with these problems, the Community Development Department must sort out the most valid means. Decisions of this sort are usually made on the basis of the planner's previous experience, knowledge, education, and expertise. It is this judgment that is entrusted to the professional that the city or town hires. However, in community development, many decisions concerning the means and the method are based on somewhat subjective "give and take" factors. Personalities and selfish ideals frequently clash with what is best for the town. Receiving feedback through surveys provides an opportunity to take the pulse of the public being served. This is particularly true 
when the issues being resolved are controversial and require much input.

In the test case, there are certainly a number of unresolved issues that are well addressed through the administration of a questionnaire. If the theory is correct, the results will solidly demonstrate the direction to be taken by the Community Development Department in the near future. With limited departmental resources, streamlining activities to determine which ones are most productive is most essential.

The survey being developed is not intended to be a "one shot" undertaking. Part of establishing a positive relationship between the town and those concerned with the problems of the downtown involve keeping the channels of communication open. If the business community can see a direct relationship between the results of the survey and an improvement in the downtown, they will be more likely to make contributions to the survey effort. (1) In this sense, the survey fits only part of a puzzle that develops over time. To isolate or freeze the implications of one survey at one point in time would not accurately

(1) Carol H. Weiss and Harry P. Hatry, "Basics in Conducting Citizen Surveys," MIS Report 16 (October $1984): 1$. 
reflect the changes brought by the passing of time.

The community development activities undertaken by a city or town are active and dynamic by nature. Turnover in property owners, merchants, city or town officials, and business organizations is the rule, rather than the exception. Ideas and plans come and go. Depending on the size and scope of these activities, a survey should be delivered and administered at least once per year. This process allows a coordinator to achieve two primary objectives. First, it allows an opportunity to review the impact and affect of the previous policies that have already been implemented. It is possible that an idea that was widely accepted may prove to be less beneficial once in place. If this is the case, then the coordinator can set up meetings to isolate the source of a problem and achieve a new consensus. Naturally, this process works in reverse when a less popular project achieves unforeseen positive result. Second, the development of new thoughts, ideas and plans can be evaluated in a systematic fashion. The coordinator and staff have a closer contact with all interested groups and individuals than does any other one group or individual. This further legitimizes the community Development office as being best equipped to handle a survey of this kind. Before a recommendation is made 
on a policy decision, some input will have already been received.

Developed properly over several years, the Community Development Department, through the use of the survey, will have access to information that provides a basis for program evaluation. Each time a survey is administered, questions may be added or deleted according to the most pressing issues at the time. The base of information will provide the framework for an analysis of current trends in the thinking of those involved in community development activities. A long term relationship will then be established between the key planning issues and their significance in prioritizing the needs of the downtown and community development sectors. 


\section{I . METHODOLOGY OF SURVEY ADMINISTRATION}

\section{Determination of Need for Survey Design}

The framework under which survey development and administration is most productive has already been established. A dynamic planning environment with considerable public participation involvement makes the results of the survey valuable to policy makers. Once this situation exists, the methodology of survey administration becomes extremely critical to the desired results. Questions must be raised about who will receive the surveys, how many will be distributed, what is an acceptable response rate, what will be the nature of the questions, and whether the survey should be conducted by mail, in person, or by telephone. This section focuses on helpful guidelines for planners in their decision-making process.

It must be stressed that every survey will be distinct and different. There are an unlimited number of factors that define the survey and its administration. Since the community development process lends itself to the use of surveys, this 
functional area will be the one analyzed. The following is a compilation of the most significant factors needed for an assessment prior to an administration of a survey.

1. The governmental structure under which the Planning or Community Development office must operate. This varies by whether the municipality is a city or town and who is responsible for making decisions in the community.

2. Whether there exists one or several specific issues that are being resolved and whether the survey will focus attention only on those issues and their resolution.

3. Whether the survey is serving as a "feeler" to get general impressions of potential goals or actions by the Planning or Community Development office. If this is the scenario, then the broadest and largest scope of groups in the community should be able to voice their sentiments through the survey.

4. The survey must define its target audience. If this is limited to property owners or a special interest group, then all members must be included. This is generally known as a survey of the population. 
Essentially, all community development surveys must define a purpose, an audience that will participate in the feedback, and a government structure under which the results can be used to produce a course of action. Community or economic development planning is most likely to involve direct citizen participation. Therefore, surveys can provide a most desirable tool for many planners to utilize.

\section{Methodology of Survey Development Procedures}

Having established the need and priorities used for developing a survey, the planner must turn his attention to its implementation. As with the priorities, each survey will be conducted differently, and this difference will often be very significant. The following is a list of issues that are most common to the development of a community development survey. 


\section{Typical Steps in the Survey Process}

1. A definition of goals and establishing a clear purpose for the survey

2. A specific definition of the target audience and a breakdown of who will receive a survey or be interviewed. This step also includes anticipating the response rate

3. A medium for the administration of the survey, either through the mail, in person, or by telephone

4. Cost and time considerations

5. Design of the questionnaire

6. Editing, coding, and tabulating data

7. Analyze and interpret findings

8. Distribution of information to concerned parties

9. Use of information in formulating goals and policies

10. Use of future surveys to further clarify or expand on the results of the initial survey 
Ideally, every survey will be examined in detail by the planner for each of these ten steps. In anticipation of conducting a survey, the planner should address each item so that problems can be met prior to its implementation. The Stoneham community development survey will be cited as the main example throughout this project. The issues being addressed in Stoneham are very similar to those in many small to mid-size downtowns throughout the country.

Establishment of Goals and Purpose.

The rational for the survey should be clear to both policy makers and respondents. Although the voicing of opinions through a survey is easily acceptable to some, many others feel a sense of distrust or apprehension in answering specific questions posed by a governmental office. If the aim of the survey is the long-range establishment of community goals, then this should be stated up front. Or, if a specific group of downtown merchants is being queried on the viability of a downtown parking facility plan, then the target audience should be specifically defined to those being interviewed. In general, the more specific the goals or purpose of the survey, the more valuable the results will be. 
Regardless of the medium being used, the response rate to the survey will be higher if the purpose of the survey is clearly explained to the respondents. In the Stoneham survey, which was done by mail or through direct personal contact when possible, an accompanying memo was attached to the survey. It explained the goal orientation of the survey. Since this attachment was distributed in memo format, property owners, merchants, town officials, and Stoneham citizens realized that they were the selected audience. At the same time, a memo of this type can help encourage the response rate to the survey. This is achieved in two ways. First, respondents are made aware that the results of the survey will be available to interested parties. It is reassuring to know that the results will not be part of "behind the scenes" planning and that the process is an open one. (1) Second, by stressing the importance and immediacy of the issues at hand, the respondent believes their own answers will be significant. The philosophy that "my one vote doesn't count" is dispelled, since the survey is aimed specifically at a limited number of people who have as least some concern over the future of their downtown. Therefore, "one vote" under this scenario can become very important indeed.

(1) Berk, p. 2-1. 
The planner must be sure that he understands and can articulate the concept and intent of the survey. People will respond more frequently and earnestly when they feel their opinions are a significant part of the decision-making process. Making the results a matter of public record and opening up the process will reflect positively on the work being undertaken by the planner. No attempt should be made to conceal or undermine this process.

Finally, the respondents must expect that the planner's door is always open for comments, suggestions, or proposals that the Community Development/Planning office can undertake. In this sense, the first survey is merely one step in a progression.

In the Stoneham example, both long term community goal setting and short term problem resolution were integrated into the questionnaire. The primary issues addressed in stoneham include: on and off street parking, community cooperation between town officials, residents, and private interests, image problems, physical appearance, installation of planters, and an improved retail business mix. Generally, even if the purpose of the survey is directed at only one or two issues, it makes sense to incorporate some questions 
relating to long term goal setting. With the respondents answering the survey, it is possible to solicit opinions on a number of topics. It is logical to ask more questions on one survey than to ask few questions on several surveys administered at different times.

The importance of goal setting in community development planning can not be underestimated. It is important for several reasons. First, goal setting provides a sound basis for planning implementation and evaluation. Setting goals provides a positive setting under which a planner can operate. Second, when goals are clarified, the problems at hand are easier to understand, especially in view of many complex issues. Third, planning with a set of goals in mind lends itself to community involvement and participation. This is due to a consensus of ideas that, when coagulated, can produce meaningful results or action. Finally, when goals are established, avenues for citizens or actors to state their concerns and needs are available. (1) Thus, goals are themselves a positive form of action that can be changed, altered, or refined. Goal setting is particularly important in the community development context where frustration and

(1) Frank J. Smith, and Randolph T. Hester, Community Goal Setting (Pennsylvania: Hutchinson Ross Publishing Company, 1982), p. 40 . 
disappointment with failed plans occur all too frequently. The town of Stoneham, through its earlier policies, has suffered from these symptoms.

Specific Definition of the Target Audience.

Once the goals have been defined, it is necessary to look at who is being targeted for the survey. In most downtown commercial settings, several different actors can plan a key role in shaping policy decision making. Although every community is different, the following list categorizes the most significant actors in the process:

A. City or town officials, either elected or appointed

B. Property owners who are not necessarily merchants

C. Retail merchants or proprietors

D. Employees in general

E. Interested residents or willing shoppers

F. Members of a local development group or business organization

Depending on the emphasis of the survey, each of these groups should be represented through the survey. However, if, for example, opinions are sought on the possibility of state funding for a commercial development project, it would be most logical to obtain a higher response rate from town officials, property owners, and a local Chamber of Commerce than from the 
other three groups. The question of balancing response rate between the various groups must be addressed on the basis of the needs of an individual community. Larger communities may find it more difficult to select a balance of each group, since the issues in these cities or towns tend to be more complex. In smaller downtowns, a survey of nearly every single individual associated with community development would be advantageous .

Generally, a response of at least 30 completed surveys is considered statistically valid in the social sciences. A smaller sample can only be considered valid when the issue at hand influences far fewer people. If the purpose of the survey is to examine the establishment of goals, then 30 completed surveys must serve as the absolute minimum. Naturally, a larger return should be expected when at least 100 surveys are distributed. (1)

Once the weighting of each group is established, the planner must predict what the response rate or percent of return will be. Although this issue is closely related to the medium that is selected, a response rate must nevertheless be anticipated. The Stoneham survey was distributed by mail or through

(1) Weiss and Hatry, p. 5. 
personal contact to 78 individuals. The vast majority were handed the survey by the community development coordinator, with perhaps a dozen surveys being mailed to residential homes. A return period of approximately one month was allowed. Due to the slowness of people to respond to surveys where they must record their own answers, phone calls and reminders were frequently used to improve the return rate. This strategy was apparently successful as 42 surveys out of 78 (53.8\%) were returned to the Community Development office. By group, this percentage breaks down as shown in Table 2 .

\section{Table 2}

Breakdown of Distribution of Stoneham Community Development Survey By Affiliation

Distributed *

1. Business Merchants

2. Property Owners

3. Stoneham Residents

4. Town officials

5. Stoneham Square business groups or development corporation

6. Employees
11

12

14

19

10

12
Returned *

$7(63.68)$

$6(50.0 \%)$

$12(85.7 \%)$

$9(47.38)$

$5(50.08)$

$3(25.08)$

\section{Total}

78

$42(53.8 \%)$

* Respondents defined their own sense of affiliation, which sometimes differed with what the expectation was when the survey was distributed. 
Although there was an effort to balance the distribution where possible, frequently respondents regarded their own affiliation with stoneham square differently than did the community development coordinator. This perhaps explains the high percentage of returns by stoneham residents as opposed merchants or employees. Some of those surveyed had three or four common affiliations with Stoneham Square, and chose the nondescript "Stoneham Resident" label as the easiest to relate to.

In this survey, the community development coordinator was closely familiar with approximately half of those who received the survey. Thus, it was slightly more difficult to not complete the survey when asked. The $54 \%$ return rate is excellent, considering that only one person could distribute the survey and be responsible for its return. This experience indicates that a high return rate can be expected when fewer questionnaires are distributed. If over 100 surveys are distributed, the return rate will most likely drop to under 40\%. This is because it is difficult to establish any personal contact with so many additional people being given the survey. This rate will drop even further if a mailing is the only medium used in the distribution of the survey. Regardless of the method used, a $50 \%$ or greater return rate is 
outstanding and the result of strong efforts to get people to complete it.

In summary, the planner must weigh the importance of the survey and the responses that are received. The easiest, least time-consuming methods will bring the poorest response rates. On the other hand, individualized attention to the respondents through personal distribution will bring an improved success rate. (1) This will be particularly true in a smaller community where the community development director/planner will "know" most of the people in the community.

Meduim for the Adminstration of the Survey.

With any survey, there are essentially three different ways to obtain the opinions and attitudes of the respondents. Although each method has advantages and disadvantages, there are some clear guidelines that should be followed when considering which one will be adopted. Three different considerations are necessary before a planner can make a final decision. Cost, response rate, and time involved are the most important considerations in selecting the survey procedure.

(1) Kenneth Webb, and Harry P. Hatry, Obtaining Citizen Feedback: The Application of Citizen Surveys to Local Governments (Washington D.C.: The Urban Institute, 1973) pp. 49-50. 
This report is not intended to delve deeply into the pros and cons of each methodology as it relates to various types of surveys. From this perspective, in the majority of cases in communities with populations of under 30,000 , the personal interview technique will produce the highest response rate and most usable results. However, cost and time considerations might reduce the feasibility of this approach. The three survey methods will be examined below.

The face-to-face or personal interview proves to be most informative since respondents are usually willing to go through an interview with someone they can associate with. (1) If necessary, visual aids can also be used. In the Stoneham case, interview forms were personally handed to many of the respondents. They were asked to complete the questionnaire on their own and return it upon completion to the community Development office. This allowed the interviewee time to complete the survey and maintain a degree of confidentiality in the process. This method worked well enough to produce a $54 \%$ response rate. In larger municipalities, this approach would prove to be costly, since such a large number of questionnaires would be solicited. Where it is not too costly, the drop off or face-to-face format (if possible) will yield the (1) Ibid., pp.48-49. 
highest response rate and most informative responses. Actually, the drop off technique is a cross between the personal interview and the mailed-out survey. This approach works best when the interviewer and the respondent are familiar with each other, and cooperation is possible. Regardless of the precise technique used, the highest possible response rate is a crucial aim in the administration of the survey.

The telephone interviewing technique is most suitable for large scale political surveys where distance to the respondents becomes a factor. From the planning standpoint, this approach makes sense if a staff exists that can read and administer a survey when the target audience is available. Frequently this could involve night or even weekend calling when merchants or property owners would be available. The telephone approach is also feasible when a large number of interviews are needed in a short period of time. A drawback to this approach is the considerable amount of time needed to train interviewers and to insure quality control over the process. (1) There is limited experience in using telephone surveys in the community development process.

(1) Ibid., p. 46 . 
A mailed survey is the least predictable of the three mediums. From the cost perspective, it is the cheapest, since only the cost of printing and postage are absorbed by the Community Development office. As a rule, the mailed survey can produce more candid opinions, because it can be done privately and anonymously. Another advantage is that the survey can be done in the comfort of the home and is therefore not subject to the stress of the personal or telephone interview. (1)

In communities with larger populations, the mailing format will work best. Expecting a $25 \%$ return rate at best, a significantly great number of surveys must be mailed out. If a case can be made that the population being surveyed is highly motivated or has a considerable interest in the results, then a higher return rate is likely. In a community development survey, almost every respondent will be somewhat familiar with the issues, since the survey will only be distributed to those who have been involved with its activities in the past.

Mail surveys tend to be unpredictable for several reasons. First, the response rate may vary 15 to $30 \%$ from what was originally anticipated. Second, it is

(1) Ibid., p. 45 . 
difficult to control the returns of a particular group. In the Stoneham survey, 10 surveys were distributed to members of the local Stoneham Square Development Corporation and the Chamber of Commerce. It was expected that nearly all of these surveys were going to be returned. It is important to guage the interest level of each group being surveyed. Finally, with mail surveys, respondents may be careless and omit responses to questions or even leave whole pages blank. In these instances, with no interviewer control, the surveys must be considered invalid and unusable.

Comparisons of the three main methods of interview are summarized in Table 3. 
Table 3

Comparison of Interview Methods for

the Community Development Survey

\begin{tabular}{|c|c|c|c|c|c|}
\hline & $\begin{array}{l}\text { Interview } \\
\text { Method }\end{array}$ & $\begin{array}{l}\text { Response } \\
\text { Rate }\end{array}$ & Cost & $\begin{array}{l}\text { Time } \\
\text { Involved }\end{array}$ & $\begin{array}{l}\text { Overall } \\
\text { Result }\end{array}$ \\
\hline 1. & Personal & Highest & Highest & Greatest & $\begin{array}{l}\text { Responses } \\
\text { most valid; } \\
\text { Sample control } \\
\text { positive }\end{array}$ \\
\hline 2. & Telephone & Average & $\begin{array}{l}\text { Medium, } \\
\text { man hrs. } \\
\text { high }\end{array}$ & $\begin{array}{l}\text { Great, but } \\
\text { short time } \\
\text { period }\end{array}$ & $\begin{array}{l}\text { Worth adoption } \\
\text { with proper } \\
\text { personnel and } \\
\text { larger survey }\end{array}$ \\
\hline 3. & $\begin{array}{l}\text { Mail or Self } \\
\text { Administered }\end{array}$ & Lowest & Lowest & Least & $\begin{array}{l}\text { Suitable to a } \\
\text { large sample; } \\
\text { Useful when } \\
\text { issues are } \\
\text { critical }\end{array}$ \\
\hline
\end{tabular}

It can be concluded that when feasible, the personal interview will be most successful. However, the other methods have appropriate uses, and in a large setting, the mail survey may work the best if the issues are crucial enough. Combinations of these methods may be appropriate but can complicate the overall procedure. 
Cost and Time Considerations.

Both of these problems were dealt with in the previous section. Community development issues are usually spread out over extended periods of time, since goal setting and implementation are involved. As a result, the urgency in returning the surveys is diminished. Thus, the personal and mail procedures for distributing the survey will work best if a quick consensus or problem resolution is not needed.

Regardless of the method used, considerable hours will be needed by the office staff to adequately prepare and administer the survey. These hours translate into high costs unless volunteer staff are available to help out. If the survey is to be taken seriously, the planner will have to budget large blocks of time for a period of two to three months to complete the process from conception to conclusion. If cost is not a major factor, while time is, then the possibility of using an outside planning consultant or specialized survey development company comes into consideration. (1)

As a follow-up to the initial survey, the planner will want to consider future surveys on at least an annual basis or as the need arises. Budgeting and
(1) Berk, p. 3-1l. 
staffing for a survey ought to be included as an integral part of any presentation to the higher municipal authorities in a community at the time of budget proposals. The community development survey can serve to not only assess priorities and formulate the resolution of problems, but may also be used to evaluate the success or failure of specific programs in the past.

\section{Design of the Questionnaire.}

The actual design of the questionnaire is perhaps as critical as any of the other steps in the process. A poorly designed questionnaire will provide misleading or missing information. Slanting of the questions towards one response or another renders the results nearly invalid. Unfortunately, no true formula exists that will make for a fault-proof survey. Unless the questions being posed deal with statements of fact, they are open to various forms of interpretation. Most of the available literature deals with political surveys and how they are designed. Thus, the community development director or planner is nearly on his or her own in the development of the questionnaire. 
Every survey will be different in scope and purpose. The particular needs for the information must be examined along with the purpose of the survey prior to the formulation of the questions. Essentially five types of information can be solicited through questions in the survey. By organizing groups of questions in this way, the survey can be put together. Table 4 shows the types of questions that may be posed, and their general purpose. The last column of the table lists the numbers of the questions in the Stoneham survey that correspond to the category of question. The actual Stoneham survey appears in the Appendix. 
Table 4

Questions by survey Type

Type of Question

1. Demographic

2. Knowledge of Issues

3. Attitudinal and

Problem Identification

4. Priority setting

5. Open-ended
Purpose

Background;

Questions of

fact

\begin{abstract}
Determination
of what is

known about

community

development

activities
\end{abstract}

Reaction to

current or

existing

conditions

Evaluation of needs;

Establish

goals

Allows for comment or detailed response
Stoneham Survey

$1,2,3,9,15$

$5,16,17$

$4,6,7,8,10$,

$12,13,14,23$,

24

$11,18,19,20$, $21,22,25,26$,

$27,28,29,30$

10,30 
In terms of the ordering of questions, the early questions should move from background information to knowledge of issues to problem identification to priority setting. (1) It is essential that at least four types of questions be well represented in the questionnaire. The open ended questions can be a lower priority if respondents are not given a sense of direction in answering them, as they would in a telephone or personal interview.

The actual wording of the survey is more difficult. The order of the questions, wording, and length of the survey all can have important effects. With respect to wording, questions must be posed in such a way that people of different education and background perceive common meanings. (2) If possible, a pretest of the survey may be employed to clear up any ambiguities of misunderstandings. (3) As a general guideline, every question should be geared towards eliciting a positive or negative attitude in the response. Non-committal or "middle of the road" responses do not lead to particularly meaningful results.

(1) Harry R. Peacock, "Determining Community Needs with Community Surveys," MIS Report 16 (October $1984): 15$.

(2) Charles K. Bens, "Strategies for Implementing Performance Measurement," MIS Report 18 (November $1986): 7$.

(3) Webb and Hatry, p. 50. 
Open-ended questions may be used when attempting to investigate deeper into the reasoning of the respondent. These responses are easier to obtain through personal or telephone interviews, because the interviewee has more opportunity to express him or herself. In these instances, the interviewer can direct the answer or clarify when necessary. The interviewer needs skill and practice in making this work.

Finally, in terms of the questionnaire, thought must be given to a comparison between the initial survey and future surveys. (1) When results are to be compared from one period to another, the same wording of questions should be retained so that responses are comparable. Even minor changes in words can shift responses, as opinion polls have demonstrated.

When the planner or staff put together the questionnaire, several others should review it to come up with a workable version. This will allow input into the process and eliminate problems at a future time. When the questionnaire is developed properly with these parameters in mind, the planner is assured of meaningful results that will help shape future policy.

(1) Weiss and Hatry, p. 1. 
Editing, Coding, and Data Tabulation.

This portion of the process is straightforward. If the survey return is small enough (under 50) one or two individuals can tabulate all of the results and affix percentages in just a few hours. With larger numbers, the use of a personal computer can automatically calculate percentages and make the recording of the responses easier. (1) The open-ended questions are tabulated by recording similar responses where applicable.

The editing of the interviews insures that all questions that should have been answered were answered. Some of the questions on the Stoneham survey allowed for a skip pattern, thus resulting in some questions not being answered by every respondent. These included questions 13 and 14,15 and 16 , and 28 and 29. As with the other parts of the process, accuracy is needed to guarantee the proper tabulation.

(1) Peter I. Hechenbleikner, "Citizen Surveys: A Tool of the Trade," MIS Report 16 (October 1984):9. 
Analyze and Interpret Findings.

The initial results provide the base of information that can be built upon. The stoneham survey provided results that both contradicted and supported some pre-conceived beliefs. An analysis of some of the findings are included in section $V$, which deals with the potential of the survey to shape policy.

Distribution of Survey Results.

The community development survey is one important means for downtown actors, either private or public, to express their views about current or potential problems. When the Community Development Department undertakes a survey, it must expect the results will be available to the public. On the other hand, a guarantee must exist that individual replies on any topic are never divulged. Criticisms of governmental policy are often easier to make when the respondent knows that he or she will be protected by anonymity. If an undercurrent of dissatisfaction with policy exists, the survey provides a harmless way to vent problems to the director without fear of "reprisal." The staff that edits or conducts the survey must clearly understand that they are not at liberty to discuss the names of respondents or to identify 
individuals. Individual surveys should only be accessible to the survey staff.

Once the results have been reviewed, a summary sheet should be prepared. This sheet highlights the most significant findings of the survey in a brief, concise manner. (1) The summary sheet for the Stoneham survey is included in section IV of this report. By preparing a summary sheet, the Community Development office can distribute its basic findings to all survey participants. This can most successfully be completed by mail and can also be accompanied by a note thanking respondents for their participation. This reinforces the idea that the survey was of positive benefit and will encourage future cooperation. (2) Respondents can also request the complete tabulation from the Community Development office.

It is important that the media, relevant city and town officials, and local business or development groups also be informed of the results. For those groups that would have specific interest, the entire survey results and the summary sheet should be provided. All survey participants and business groups ought to be made aware that their opinions can be voiced through the year through the Community

(1) Weiss and Hatry, p. 7.

(2) Ibid. 
Development or Planning Office.

Use of Information in Formulating Goals and Policies.

The use of the community development survey is most helpful in assessing and revising goals and objectives. Each individual community is different, but each shares the need to evaluate its current position and the direction in which it is headed. If directly definable goals and policies are self-evident from the survey, the planner has a base from which to work to establish priorities.

Citizen participation, as it relates to follow-through on the survey and the formulation of policy, is considered later in this report. Some suggested formats for using the public opinion survey include: public hearings, open information meetings, the establishment of committees, and formulation of a citizen task force to study problems further.

\section{Use of Future Surveys.}

It is important to establish a base of information from which to work. The community development survey is one method of keeping track of the pulse of the public that is affected by the decisions made at City or Town Hall. An initial survey 
can only look at the entire scenario at a given moment. However, when a progression of pictures is provided, the shaping of policies and priorities can more accurately be established.

Depending on the complexity of issues, sources of funding, and specific problems at hand, a community development survey can become a regular part of the planner's itinerary. In Stoneham, it is estimated that an annual survey will adequately provide the type of information needed to establish goals and identify problems and solutions.

The survey must be carefully evaluated at each distribution to be sure that the issues are current and topical. The sample being sought must also closely represent the latest cross-section of downtown interests. It is not enough to repackage old information in a new setting. The survey must keep current yet build upon the information provided by surveys in the past. 
It is clear from this discussion that community development surveys can take many forms and directions. The importance of setting goals and the establishment of priorities cannot be underestimated. Whenever possible, the survey must reach out to as many actors as actually participate in the process. The survey must be administered in a way that will invite openness on the part of the public and earn their respect for the Community Development or Planning Department in its decision-making process.

Finally, the results of the survey can be seen as a crucial link from public perception to the final implementation of policy. The survey can form a bridge in that regard. Once attitudes towards existing conditions are established, the survey can provide answers to why the attitudes exist, and what steps can be taken to improve them. Thus, a re-evaluation of priorities and an establishment of goals leads to better decision making. 


\section{SURVEY RESULTS AND \\ POLICY ALTERNATIVES}

This section presents the summary of results of the Stoneham community development survey. The survey was conducted during March and April 1987 in the town of Stoneham, Massachusetts. Results of the survey are based upon 42 returns prior to April 13, 1987.

This section and the Appendix include the following items:

1. Memo to survey participants (Exhibit I)

2. A summary of findings that relates the most important results of the survey (Exhibit II)

3. The final distribution and return percentages by affiliation for the survey (Exhibit III)

4. Policy Alternatives

5. The actual survey results (Appendix) 


\section{TOWN OF S T O N E H A M}

35 CENTRAL STREET

MASSACHUSETTS 02180

Telephone

617/438-1651

LOUIS A. MERCURI

COMMUNITY DEVELOPMENT COORDNATOR

EXHIBIT I

TO: $\quad$ Property Owners, Merchants, Town Officials and Stoneham Citizens Concerned with Stoneham Square

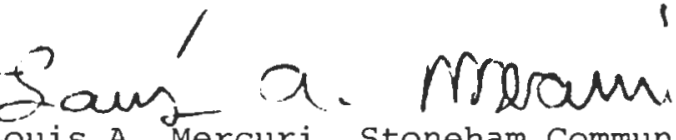

FROM: Louis A. Mercuri, Stoneham Community Development Coordinator

DATE: January 14,1987

RE: $\quad$ Stoneham Square Survey

I'm taking the time to distribute to you a survey that will help shape the policies and priorities that will affect the future course of stoneham Square. Merchants, property owners, Town officials, business grcups and interested citizens like yourself, are being asked to contribute their thoughts and ideas through this survey.

The results of the survey will be available to all interested parties. In the past year, considerable money and effort have been expended to improve Stoneham Square with funds from the Massachusetts Small Cities Grant Program. Still, other issues such as parking, beautification, traffic congestion and promotional ideas need to be addressed.

Please take a few minutes to complete the attached survey and return it to the Community Development office at Stoneham Town Hall. The address is 35 Central Street, Stoneham, MA 02180 if you return it by mail.

Your responses will help form the ideas and plans that will improve overall conditions in stoneham square. The importance of these issues will directly impact the viability of the Square for years to come.

Please be in touch with me at 438-1651 and I will try to be of assistance.

LAM : az

Enc. 


\section{Exhibit I I}

Summary of Significant Survey Findings

* $95 \%$ of the respondents would be more likely to use the Square if more parking were available.

* $79 \%$ believe the Square has improved in physical appearance recently.

* $80 \%$ believe the image of the Square has improved or stayed the same.

* $33 \%$ identified the parking problem as the one key issue in Stoneham Square. The poor retail mix at $29 \%$ followed closely in second.

* $50 \%$ identified the Stoneham Board of Selectmen as best able to take the lead in handling the parking problem.

* $88 \%$ believe that pride in maintaining the Square is a serious problem.

* 27 of 42 respondents or 648 believe that the purchase of commercial property in the Square would either be a good or excellent investment at this time. $62 \%$ believe this is so because of either the unrealized potential in the Square or because of the possibility of bringing in new businesses. 
* $12 \%$ of the respondents were not familiar with the 1986 Massachusetts Small Cities Grant that provided funds to improve the downtown.

* 90\% believe the recent facade improvements make a significant difference to the appearance of the Square.

* Off-street parking (62\%), on-street parking (57\%), physical upkeep of buildings (52\%), and pride in maintaining the Square $(52 \%)$ were identified as the items of top priority for the future of the Square.

* A community profile book and the installation of planters were rated as low priorities.

* $95 \%$ believe a development proposal for a parking facility in Stoneham square to be critical to the future of the square. 


\section{Exhibit II}

Final Distribution of Survey by Affiliation

78 Total Distribution

Affiliation or

Business Organization

Distributed * Returned

1. Merchant in Square

11

$7(63.6 \%)$

2. Property Owner

12

$6(50.0 \%)$

3. Stoneham Resident

14

$12(85.7 \%)$

4. Town Official

19

$9(47.3 \%)$

5. Stoneham Square Development Corp.

10

$5(50.0 \%)$

6. Employee

12

$3(25.0 \%)$

Total

78

$42(53.8 \%)$

* Based on the perceptions of the community development coordinator of how individual respondents would affiliate themselves 


\section{Policy Alternatives}

An analysis of the summary of significant Findings (Exhibit II) and the actual survey results (Appendix) is particularly revealing. From this analysis, three problem areas are particularly significant. First, the lack of available on and off street parking is the foremost issue on the minds of the Stoneham respondents. $95 \%$ would use the Square more if additional parking were available. Second, 29\% or nearly one-third of those surveyed found the poor retail mix to be a problem almost as important as the parking issue. Finally, $88 \%$ believe that a lack of pride in maintaining the Square is a serious problem.

The importance of each of these issues is a top priority of the Community Development Department. Although several alternatives may exist to answer each concern, at least one clear plan ought to be pursued for each. Naturally, the effect of an increase in

available parking would promote new possibilities to improve the retail mix. Thus, one or more alternatives may prove instrumental in helping to resolve several other areas of concern. 
The town has already sought help on the parking issue. In late 1986, through the efforts of the Community Development office and a consultant, a site-specific parking proposal was approved. The proposal calls for an off street parking facility with a capacity of 157 cars to meet the parking demand. The State of Massachusetts operates an Off-Street Parking Program that will reimburse cities and towns $75 \%$ of the cost of an approved facility. Once all costs are figured, the Stoneham proposal is projected to cost in the vicinity of $\$ 2$ million. Currently, this proposal, with the full endorsement of the Board of Selectmen, is pending at the state level. If this plan is unsuccessful, alternative sites can be chosen for another application. In the interim, there is little immediate action that the town can take to improve the situation.

The poor retail mix appears to be a function of two factors. Without sufficient parking, it will always be difficult to attract higher quality businesses to locate in Stoneham Square. Also, the exterior physical appearance of existing structures is not inviting to prospective retailers. It is not likely that property owners will invest in the improvement of their facades unless given some incentive. The town has worked to produce the means 
for these improvements to be undertaken. By applying for and receiving Community Development Block Grant (CDBG) funds from the state, property owners are eligible for a $50 \%$ facade rebate program on approved renovations. This program is operated by the Community Development Department. The town will continue to apply for these annually competitive funds, until the downtown is sufficiently renovated. At that point, painting of buildings, renovated storefronts, signage improvements, and storefront design improvements will have taken place. This work will prove to be an incentive for retailers to locate in Stoneham Square in the years to come. This action will substantially enhance the possibility of an improved retail mix.

Finally, the lack of pride or community concern and respect for the Square is apparent. This issue is more psychological than tangible in terms of specific program proposals. An improvement in parking, building infrastructure, and retail mix will lead to an eventual attitude change by residents, merchants, and property owners toward their downtown.

From the standpoint of the Community Development Department, an awareness of the lack of pride in the Square can be best dealt with through the Stoneham Square Development Corporation. This quasi-public, 
private, non-profit group can sponsor activities in the downtown that will attract shoppers. Community public relations events work best in this regard. For instance, the type of activities that suggest themselves include: a Stoneham Square awareness day with merchants offering special discounts on goods and services, band concerts, an art exhibit, singing groups from the public schools performing in the Square, a cookout or seafood supper, and a magic show. If the community believes there are activities happening in the downtown, they will be more likely to take advantage of the special services a smaller downtown offers. At this time, none of these activities take place in Stoneham Square. The Community Development Department must work closely with the Development Corporation to provide some impetus for these ideas. It is up to the Development Corporation or even the Chamber of Commerce to sponsor the activities. These active steps will improve the retail spirit, viability of the Square, and the community pride in the downtown.

All of these proposals are part of an overall redevelopment plan for Stoneham Square. The use of the survey has proven instrumental in formulating goals and objectives to help shape community development policy. Chapter $\mathrm{V}$ examines the use of the survey and how it can further serve the community development process from 
goal formulation to implementation. 


\section{ANALYSIS OF SURVEY RESULTS LEADING TO \\ POLICY FORMULATION}

\section{Use of Data}

Much of the existing literature on survey development is concerned with the procedure used in the administration of the survey. Section III of this project demonstrated several steps that are necessary to produce a meaningful survey. Unfortunately, little attention has been focused on what can be developed with the valuable information that was obtained. This analysis believes that the results of community development surveys are an integral part of an extended planning process.

The only basic limitation to the considerable advantages of survey development comes from those individuals who administer the survey. Without proper training or expertise, a poorly designed and implemented survey can produce results that are opposite to actual conditions. "Many agencies have only recently begun to include social scientists on their staff and several still do not have this 
expertise internally. The cost of hiring a consultant in this field is often high." (1) These arguments will be reviewed again in section VI, which deals with the evaluation of the survey methodology.

The raw numbers and percentages generated by a survey are very important. Results that are unexpected can be eye-catching. However, the usefulness of the survey is not limited to this base information. By investigating the data at two or even three levels below the surface, extremely valuable information can be derived. For example, in the Stoneham survey, 37 of the 42 respondents indicated on question $12 \mathrm{f}$ that pride in maintaining the Square was a serious problem at this time. This represents $88 \%$ of those surveyed. It is important to identify which groups believe this to be the case. By using question 1, the following matrix can be established.

(1) James L. Creighton, The Public Involvement Manual, (Cambridge: Abt Books, 1981), p. 250. 
Table 5

Cross Tabulation Matrix

Merch- Owners Resi- Offi- Busi- Employed

(19) Very ants

dents cials nesses

Serious

3

4

7

2

1

2

(18) Somewhat Serious

2

2

5

4

4

1

(37)

5

6

12

6

5

3

From this analysis, it can be concluded with some confidence that members of local business groups or the Stoneham Square Development Corporation do not believe lack of pride in the square is as serious as it is for the property owners. $67 \%$ of owners but only $20 \%$ of business groups or the Development Corporation believe pride to be a very serious problem.

The establishment of this type of matrix is known as a cross tabulation. With a large number of questions, the possible number of cross tabulations will increase dramatically. This process can even be developed to a third level. For instance, in the example above, it is possible to determine the number of property owners who consider the image problem in the square to be very serious and by whether they placed a high priority on a community profile book (question $20 \mathrm{~m}$ ). 
There are three specific issues to consider in the use of cross tabulations. First, data can be brought to life when it becomes possible to pinpoint attitudes of specific groups for positions taken in other parts of the survey. When the issue or question in doubt is critical, this type of analysis is extremely valuable to the planner. However, unless computer capability exists, this kind of analysis can be long and difficult for even just a few variables. If the Community Development or Planning Department intends to utilize surveys extensively, a home computer with basic programming capabilities should be able to complete a sorting or cross tabulation of variables. The availability of this information on computer will be very helpful for comparisons with other surveys. Finally, the use of cross tabulations gains statistical significance when there are large numbers of surveys to work from. It is often difficult to draw valid conclusions if an individual cell of a cross tabulation contains only 5 results. Generally speaking, this methodology becomes more important for large-scale political surveys or city-wide surveys, where the number of overall responses is great. Overall, the use of cross tabulations in the stoneham survey appears less useful. 


\section{Analysis of Information}

Even the best designed questionnaire has the built-in possibility of bias. The results of the survey can only explain the questions that were asked and not the questions that were not asked. Prior perceptions of the community development environment will lead the planner to develop questions relating to what he or she thinks the issues and priorities should be. In the Stoneham survey, the issues of parking, community pride, poor retail mix, and lack of cooperation between business owners were seen as the most important. The results of the survey supported those claims. It is therefore possible for the survey instrument to become a self-fulfilling prophecy. The survey developer must guard against this possibility and be willing to accept results that are different from preliminary expectations. In future surveys, this is especially important since underlying changes may not have been detected by the community development officials. Thus, maintaining open channels of communication and "knowing" the community will produce more accuracy and reliability in the results. 
The use of interpretation is a crucial factor in the analysis of the results. Although the survey may be designed and administered by the Community Development or Planning Department, various interest groups will look at the results in different ways. Prior to the establishment of goal setting and priorities, an opportunity must exist for the involved parties to meet or prepare their own description of what the results show. As Creighton points out in his book, the "Public Involvement Manual," the "various groups will interpret the results of a survey in the way that is most favorable to their position. Although the area of controversy may be somewhat more limited as a result of survey findings, the public controversy will not be eliminated. Thus, the results of the survey may pose new or unexpected questions that had not been previously thought of." (1)

\section{Converting Results to Goals and Policy Statements}

The results of surveys are unique partly because they quantify perceptions and can translate soft perceptions into hardened data. An important separation can be made between proposals that have a substantial backing and those that do not. The planner
(1) Ibid. 
must at least consider actions that a high percentage of the constituency approve of. For example, in the Stoneham survey, the results of the questions dealing with parking made this issue clear-cut. In the survey, $95 \%$ consider parking to be a serious problem, 93\% consider the issue to be a high priority, and $95 \%$ believe the construction of a new facility to be essential to the future of the Square. The strength of this response is a substantial indicator of the need for the town to quickly address this problem. The survey will also show what issues or items are of a much lower priority.

Although the community development survey will help define problems and resulting goals and priorities, it will not be as useful in the implementation of any specific course of action. The actual tactics of the development of an overall plan requires the considerable expertise of engineers, planners, architects, and consultants. If proposals of any type are to be introduced into the questionnaire, it is crucial that they be discussed in terms of priorities and goals and not in very specific terms that may change under various conditions. 
Having brought the needs and concerns of those affiliated with the downtown into focus, it is necessary to provide a forum to establish goals and priorities. This can be initiated by distributing the results of the survey to spokesmen of the groups that participated in the questionnaire. At that point, the planner may request individual meetings with these representatives to more closely examine the findings. It is suggested that the findings sheet prepared by the office also be disseminated to these individuals prior to the meetings. In Stoneham, this can be accomplished through gatherings with officials of the Stoneham Square Development Corporation and the Chamber of Commerce. At the meetings, a review of significant findings to determine a starting point or direction can be discussed. Once this is complete, the planner may further open up the process by reaching out to all of the downtown constituents.

\section{Developing Goals and Priorities Through Community Participation}

The task of bringing clearly defined goals to actual objectives requires a number of considerations. This is part of the planning process that originates with an analysis of existing conditions and, if successful, results in complete implementation. (1) The 
closer the process moves toward implementation, the further away it moves from the direct results of the survey. However, it is important to remember that the survey helped lay the groundwork for the further steps in the planning process.

In establishing goals and priorities, every effort must be made to involve community participation. In economic or community development planning, the issues are emotional and political, based on years of established background. In other words, the issues often require less technical know-how and more of a "what will work" philosophy. This is also the case in the town of Stoneham where property owners and some town officials have been involved with the same issues for years. In this setting, a coalition between the newly-formed business groups, property owners, and town officials will most likely affect changes to improve parking, the retail mix, and the general image of the Square.

Several mediums are available to promote the results of the survey to a finalizing of goals and concrete objectives. The most obvious and perhaps most effective of these involve open process techniques.

(1) Avrom Bendavid-Val, Local Economic Development Planning From Goals to Projects (Chicago: American Planning Association, [1980]), p. 5). 
Think tank sessions, neighborhood meetings, and community meetings are all possible means of generating goals and priorities. In stoneham, the Chamber of Commerce sponsored an all-day downtown revitalization seminar in May 1986. This forum gave all factions of the local community development arena an opportunity to speak on goals, priorities, and proposals. Although the forum was successful, the incorporation of the recent survey results was not possible. Thus, the framework for discussion was more loosely defined than it would have been if it had the benefit of the survey and its results. Similarly, community or neighborhood meetings give everyone concerned with the issues an opportunity to voice their views on problems in the downtown. Under these scenarios "citizen transactions are personal and face-to-face with high potential for participation." (1) Effectiveness depends on local interest and skill of indigenous citizen organizers. The open process form of goal setting is not only inexpensive, it is also consistent with the desire to make community development planning a participatory process.

The actual formulation of objectives moves one step further into the process. At this point, the specific results of the survey may not be closely (1) Smith, p. 47 . 
related to the actual tactics of delivery or finally implementing a proposed plan of action. Here, the planners may rely on an array of professionals to precisely define the actual proposal objectives. In Stoneham, the construction of an off-street parking facility was thought to be a top priority of the town. However, the questions of site selection, adequate access, and site feasibility must be resolved to produce an actual plan of action. In fact, a private consultant was hired by the town of Stoneham to provide some solutions. Public meetings were held to give citizens an opportunity for input. Some of these meetings were poorly attended. Had the community development survey results been available prior to these meetings, less confusion and greater degrees of citizen participation would have been possible. At this point, the proposal remains on hold until problems with State-assisited funding for the facility can be worked out.

The blending of goals with objectives must be accomplished by the Community Development office with endorsement from other city or town officials. If a specific proposal is to be approved by the Board of Selectmen or City Council, then considerable political backing or support may be needed. Many of the best thought-out ideas are often stopped at this stage when 
emotional or political interests become involved. The needs of the constituent community through the survey must not be overlooked even at this stage. In Stoneham, an endorsement is accomplished through the Board of Selectmen by a majority vote of the five members.

To summarize, the system of goals and objectives provides a consistency and continuity to the planning process. According to Bendavid-Val, "the practical intent of every goal should therefore be satisfactorily expressed through the performance targets; that is, it should be today's judgment that - if all the objectives are realized by the times specified - satisfactory progress has been made toward achieving the stated goals." (1) The importance of the survey results produce a furthering of the planning process from conception to realization or implementation. At a later point, the survey may be used to evaluate the success of the policy changes.

(1) Bendavid-val, p. 15. 


\section{EVALUATION OF SURVEY METHODOLOGY}

The development of surveys and their use in many fields is a social science technique that has existed for many years. To comment on their validity in various settings is beyond the scope of this project. Needless to say, survey development in the field of planning, or specifically, community development, has not been explored in any detail. This study has looked closely at the possibilities that exist in this specialized area.

\section{Comparisons to Existing Literature}

In the general field of planning, a somewhat cursory examination is given to survey methodology and development. The emphasis is instead placed on the skilled observations of the planner to become fully aware of the environment that he operates in. Data collection and the responsibilities of the department in the entire city or town framework are given greatest attention. All of these techniques are extremely useful in producing recommendations for policies and developing goals that are consistent with the needs of the community. However, the role of surveys in this 
process has been primarily discouraged because of the many pitfalls that occur when mistakes are made in the administration of the survey.

A careful review of existing literature points out the many difficulties that are encountered. For example, "citizens often exhibit a low level of interest in and knowledge about the daily operations of municipal government." (1) As a result, those surveyed will be forming general impressions on topics they know very little about. Webb and Hatry's work called "Obtaining Citizen Feedback: The Application of Citizen Surveys to Local Government" defines 9 areas that are likely to produce invalid or inaccurate information generated by surveys. (2) Creighton, in the book "The Public Involvement Manual," notes that it is also true that various groups will interpret the results of a survey in a way that is most favorable to their position. (3) Most sources are also consistent in claiming that surveys can be a rich source of information to evaluate the operating performance of a municipal department.

The major point of contention in this thesis is that the proper administration of surveys is an

(1) Bens, p. 7 .

(2) Webb and Hatry, pp. 33-42.

(3) Creighton, p. 250. 
indispensable part of the community development process. Planning literature in general does not address when surveys are useful, the importance of surveys as an ongoing process from year to year, and the need to have surveys undertaken in a very professional manner. Some sources offer a general description of the validity of surveys, (1) others are concerned with questionnaire design and administration of the form. (2) Finally, an exploration of the validity of surveys at specific points in the planning process from conception to implementation is not undertaken.

The fields of political polling, market research, statistical analysis, social psychology, and others utilize surveys as an integral part of their work. Although surveys are used and administered daily in the area of planning, the level of sophistication to which they are developed is behind other fields. As a result, this rather complex method is not applied properly in the vast majority of cases. Even sample questionnaires that are presented as "models" in existing literature provide little information of real value to the planner seeking to develop a questionnaire in his or her own community. Although survey

(1) Creighton, pp. 249-251.

(2) Berk, pp. 8-1 to 8-17. 
development is only one of several feasible methods of learning about the community, it is an area that needs further refinement and development in the planning sphere.

\section{$\frac{\text { Practicality of Surveys in the }}{\text { Community Development Context }}$}

Community and economic development activities in a commercial downtown usually result in decisive forms of action. Priorities are usually placed on immediate revitalization through facade improvements, improved retail mix, the expansion of parking, and a rebirth of the downtown. Goals, priorities, and objectives are extremely valuable to the Community Development or Planning Department in this setting. This is particularly true in Stoneham where many community development participants seek to gain influence over town officials concerning priorities. The wide range of actors involved in these activities produces a variety of pressures that are exerted on policy makers. The proper application of the community development survey will be invaluable in the decision-making process.

Dynamic forces are constantly at work in the community development setting. Property owners of commercial or retail parcels will come and go at frequent intervals. City and town officials, whether 
elected or not, will also be changing constantly. What was true two years ago will seldom be the same in the current environment. The larger the community or downtown, the greater these changes are likely to be. The community development survey permits a snapshot of the interplay of many factors at one given point in time. If the survey is designed often enough to keep pace with change, it will prove to be an invaluable tool for charting progress and direction over time.

Attitudes toward policies and actions can be quantified through the survey. Many community development problems involve solutions that are likely to alienate or distance some groups from the process. For example, in stoneham, the likelihood of using eminent domain to obtain space for a parking facility would not be warmly received by residents who could recall a building existing for 30 to 40 years. Even though the planning arguments for a parking facility are valid, many would oppose eminent domain on the principle that they believe it is unfair. Some attitudes are preconceived and will remain present no matter what is actually proposed. These sentiments can be best obtained through a survey where, to some extent, the respondent is anonymous. 
The degree of complexity of the issues involved is also significant justification for use of the survey. Through its use, the level of knowledge of the issues at hand is examined. When issues are not understood, the Community Development Department can increase public awareness and set the record straight. Even where the issues are complex, a common denominator such as a goal statement can clarify the situation. By asking specific questions with specific responses, it is possible to untangle several complex issues and at the same time gain a better understanding of the attitudes of the constituent community. With various interest groups exerting influence on public officials, the need to sort out the positions of these groups on various issues becomes critical. (1) In Stoneham, a community of just 22,000 , as many as six interest groups may be interested in an issue such as parking. The larger the community, the greater the number of groups that will want to become involved in the goal formulation or decision-making process. The survey allows this opinion to be quantified and separated by group.

Finally, factors beyond the control of city or

(1) Bruce Clary and Lee Perlman, "A Framework for Citizen Participation: Portland's office of Neighborhood Associations," MIS Report 18 (September 1986): 2 . 
town officials may be indicated through survey questions. For a downtown revitalization to occur, national or regional economic conditions must usually be favorable. The overall business climate (that is, interest rates, inflation, and unemployment) play above what can be controlled at the local level. Also, eligibility for State or Federal programs will change as Congress chooses how much to appropriate for Community Development Block Grant (CDBG) programs. The success of the local program is very directly tied to conditions at the macro level. (1) Questions 13 and 14 in the Stoneham survey, dealing with the purchase of commercial property in the square, reveal the confidence level individuals express in the overall economic climate.

The community development survey can closely scrutinize any of these elements, or can examine a combination of all of them. Being able to quantify this information brings the planner a step closer to monitoring the community development picture.

(1) Philip Favero, Local Economic Development: A Strategic Approach, Handbook, (Washington: International City Management Association, 1984), p. 4 . 


\section{Overall Survey Function in Planning}

Transportation, environmental planning, economic development, housing, and policy analysis are other significant functional areas of planning. Each has its own relevance for an application of survey use. It is not the purpose or intent of this thesis to discuss in any detail the application of survey development in these fields. However, some basic guidelines can be established that provide insight as to when surveys are most useful.

Surveys appear to be most practical when some or all of the following conditions exist:

1. When public participation in the planning process is high and residents of interest groups have a high degree of interest in the outcome of the issues

2. If surveys of citizens attitudes toward the municipality and its services can be helpful in discerning satisfaction levels 
3. Where the issues are not overly complex or technical and can be understood by the general public

4. When goal consensus from several interest groups is needed

5. Where staffing levels and cost considerations are sufficient to adequately administer the survey

6. When alternative proposals are promulgated that differ in concept sufficiently to provide a sharp difference of opinion

7. When the planner is new to the community and wants to gain a better understanding of existing conditions

8. Where the planning environment is dynamic and constantly changing

Survey development is beneficial in analyzing any aspect of the planning process from conception to implementation. Regardless of the field of specialty, this process is followed in any course of action that might be taken. The individual peculiarities of the planning setting must be examined against the set of criteria described above. 
VII. CONCLUSIONS ON THE VALIDITY OF SURVEY METHODOLOGY

This thesis has highlighted every important aspect of survey development as it relates to community development planning. At this point, it is important to step back and analyze the key role that this methodology will play in the future of this functional area of planning.

\section{Need for Continuation of the Survey Process}

The community development survey is not an end in itself. Conclusions can be drawn, and goals, objectives, and policies can be established based on its results. However, the need to constantly re-evaluate conditions to keep up with changes that have occurred is of nearly equal importance. The planner or policy maker must be very careful not to stick dogmatically to the results of a survey if it has become outdated. 
By establishing a well-defined and carefully constructed survey, the planner has at his disposal a powerful tool for use in many different situations. For example, official records often provide useful information that supplements and amplifies survey data. It also becomes possible to cross analyze sets of data against each other.

Maintenance of this information bank becomes critical. By establishing the criteria for future surveys, the planner has a base from which good policy decisions can be made. Therefore, it is important that future surveys be looked at from the perspective of the change that has taken place since the development of the last survey. If old issues die and are replaced by new ones, new questions can be added to the questionnaire.

The effect of policies that are implemented in part as a result of the survey can also become a source of future evaluation. It is possible to incorporate questions that relate to the overall performance of the Community Development or Planning Department over time. (I) Trend analysis is also useful to assess effectiveness and efficiency vis-a-vis long term goals and objectives. Once again, comparisons between one

(1) Bens, p. 10 . 
period and others can be affected by conditions outside the control of the staff or management. These changes could include the effects of inflation, departmental cutbacks, changes in management, or loss of state, regional, or federal funding sources.

In the Stoneham example, the 1987 survey was the first attempt to quantify the perceptions of the community development actors. Based on the needs to re-evaluate the current situation, another survey may not be administered for at least one year. It is important for effective action resulting from the survey to take place. However, if some action is not forthcoming, later surveys may meet with apathy, if not outright non-cooperation. (1)

\section{Purposes of Survey Development}

The importance of survey development in the community development planning process is the cornerstone of this thesis. At this point, it is logical to summarize the main advantages of the administration of a survey in the community development framework. These conditions operate under the assumption that staff time, funding, and local support exist to implement the survey.

(1) Weiss and Hatry, p. 1. 
1. The questionnaire serves as a method for determining whether the activities of the Community Development office are understood within the framework of the process.

2. The survey provides insight into what perceptions exist relative to the community development context.

3. The survey establishes priorities and consequently goals that help shape policy.

4. Perceptions of specific objectives and proposals may be gained prior to their adoption. The survey provides a vehicle for community support of these objectives and proposals.

5. When administered several times over a long period, the survey is a source of valuable data for the Community Development Department. The survey can also be used to evaluate change in this dynamic envi ronment.

6. The survey is a forum for self-evaluation of the policy implemented by the department, as well as an evaluation of the actual performance of the department. 
In terms of process, the survey instrument can be used from the first point of evaluating existing conditions to the examination of implemented policy. From the previous analysis, the analysis of the results leading to goal formulation may be of greatest benefit to the planner. Goal formulation is often synonymous with public participation. This is particularly true in the community development context. Providing the results of the survey to those concerned with downtown activities gives individuals the opportunity to be heard on many different issues.

\section{Conclusion on the Validity of the Survey Process}

The field of survey design and research is a relatively recent phenomenon in the social sciences. The use of surveys is a method of quantifying attitudes, perceptions, feelings, and knowledge on many different subjects. With the advent of sophisticated computer technology, a vehicle exists to quickly transform large amounts of data obtainable through surveys into a forum for positive action. As public issues continue to grow in number and complexity, surveys appear to be a way to gain a better understanding of what is taking place. 
Existing literature in planning does not place a particularly high priority on the validity of this methodology. However, in other fields such as political science, public administration, marketing, psychology, sociology, and economics, survey techniques and methods are more advanced. Each of these fields plays a certain role in many areas of planning. Planning could also be viewed as a loose synthesis of each of the areas mentioned above. As a result, it is difficult to understand why planning has not given a more significant role to the design and development of the survey instrument.

Every functional area of planning has the potential to utilize the survey as a means of gathering some form of information. The community development setting is particularly conducive to this methodology. Wherever change is frequent and many interest groups are concerned with the outcome of policy decisions, the need to continually use surveys is uncontested. This need is amplified as the community grows larger and the issues become more involved. To be responsive to the demands of the constituency, a method must exist to closely monitor changes as they occur. 
The public participation aspect of survey development is especially appealing. Without great cost, the opinions of a large number of individuals can be sought at once. Frequently, actors such as property owners who can not attend evening public meetings, are given an opportunity to express their views where they otherwise might not collectively be heard. Also, when administered properly and without sampling error, the planner can point to the results of the survey as a key factor in his or her decision making. This is not to make the survey the scapegoat for poor policy, but rather to help tip the scales in a process where public participation is valued.

Further investigation into the role of survey development in planning is needed. This report strongly believes that this methodology is an integral part of the community development process. By improving the application of surveys, planners and community development officials will gain in many ways from the information they obtain. In an era of information proliferation and associated technologies, the necessity to examine quantifiable data is extremely justified. Planners can work toward this goal by closely examining the need for using the survey development methodology. 


\section{APPENDIX \\ 1986 STONEHAM COMMUNITY \\ DEVELOPMENT SURVEY}

Results based on 42 responses

Please use DK/NA if you are not sure of an answer.

I. EXISTING CONDITIONS IN STONEHAM SQUARE

1. With respect to Stoneham Square, which one of the following best describes your affiliation?

1. Merchant in the Square - 7(16.7\%)

2. Property owner in the Square - 6(14.28)

3. Stoneham resident - 12(28.6\%)

4. Town of Stoneham official or employee $9(21.4 \%)$

5. Local business organization or development group - 5(11.9\%)

6. Employed in the Square - 3(7.1\%)

7. $\mathrm{DK} / \mathrm{NA}-0$

2. Which one of the following reasons is most likely to bring you Stoneham Square on a typical day? Is it:

1. Business or meeting purposes $-7(16.7 \%)$

2. Shopping in the Square - 14(33.3\%)

3. Traveling through the Square to reach another destination - 3(7.18)

4. Running a business, or being employed in the Square - 16(38.1\%)

5. $\mathrm{DK} / \mathrm{NA}-2(4.7 \%)$ 
3. For how long a period of time have you been directly involved with the activities in Stoneham Square? Has it been:

1. Under 2 years - $9(21.4 \%)$

2. 2 - 5 years $-6(14.28)$

3. 5 - 10 years $-9(21.4 \%)$

4. $10-20$ years - $10(23.8 \%)$

5. 20 - 30 years $-5(11.98)$

6. 30 years or longer $-3(7.18)$

7. DK/NA - 0

4. Stoneham Square is becoming much more appealing because of the interesting things happening there. Would you:

1. Strongly agree $-6(14.28)$

2. Mildly agree - $15(35.7 \%)$

3. Mildly disagree - 13(31.0\%)

4. Strongly disagree with this statement? $7(16.78)$

5. $\mathrm{DK} / \mathrm{NA}-1(2.3 \%)$

5. In 1985, the Town of Stoneham was the recipient of a Massachusetts Small Cities General Fund Grant. As far as you know or understand, which of the following kinds of improvements were eligible under this program?

Was eligible was not eligible DK/NA for Grant for Grant
a. Painting of exterior $31(73.8 \%)$
of buildings
$4(9.58)$
$7(16.78)$
b. Providing for of $f$ street parking for
$15(35.88)$
$19(45.28)$
$8(19.08)$ businesses
c. Route 28 recon- struction
$12(28.6 \%) \quad 20(47.6 \%)$
$10(23.88)$
d. Commercial sign
improvements
$31(73.88)$
$7(16.78)$
$4(9.5 \%)$
e. Interior business
renovations
$4(9.5 \%)$
$23(54.88)$
$15(35.78)$
f. Home improvements
$13(31.0 \%)$
$8(19.08)$
$21(50.08)$ 
g. Installation of awnings

h. Sidewalk improvements

i. Stoneham Square Parking Study

j. Facade improvements

k. Architectural design services

1. Land acquisition

$$
28(66.78)
$$$$
7(16.78)
$$$$
16(38.18)
$$$$
18(42.88)
$$$$
22(52.3 \%)
$$$$
13(31.08)
$$$$
32(76.28)
$$$$
5(11.98)
$$$$
26(61.98)
$$

$$
4(9.58)
$$

$7(16.78)$

$$
17(40.48)
$$

6. A greater supply of parking in Stoneham Square would make you more likely to stop and use the Square. Would you:

1. Strongly agree $-28(66.7 \%)$

2. Mildly agree - $12(28.6 \%)$

3. Mildly disagree $-2(4.7 \%)$

4. Strongly disagree - 0

5. DK/NA - 0

7. Looking back since you became involved with the activities in Stoneham Square, would you say the Square has improved in overall physical appearance or has it become worse in physical appearance?

1. Improved - 33(78.6\%)

2. Stayed about the same - 3(7.1\%)

3. Become worse - 5(11.9\%)

4. $\mathrm{DK} / \mathrm{NA}-1(2.3 \%)$ 
8. How would you compare current conditions in Stoneham Square with the way things were when you first became involved in the activities of the Square? For each item on the left, please indicate whether that issue has improved since you became involved with the Square, if it has stayed about the same, or if it has declined.

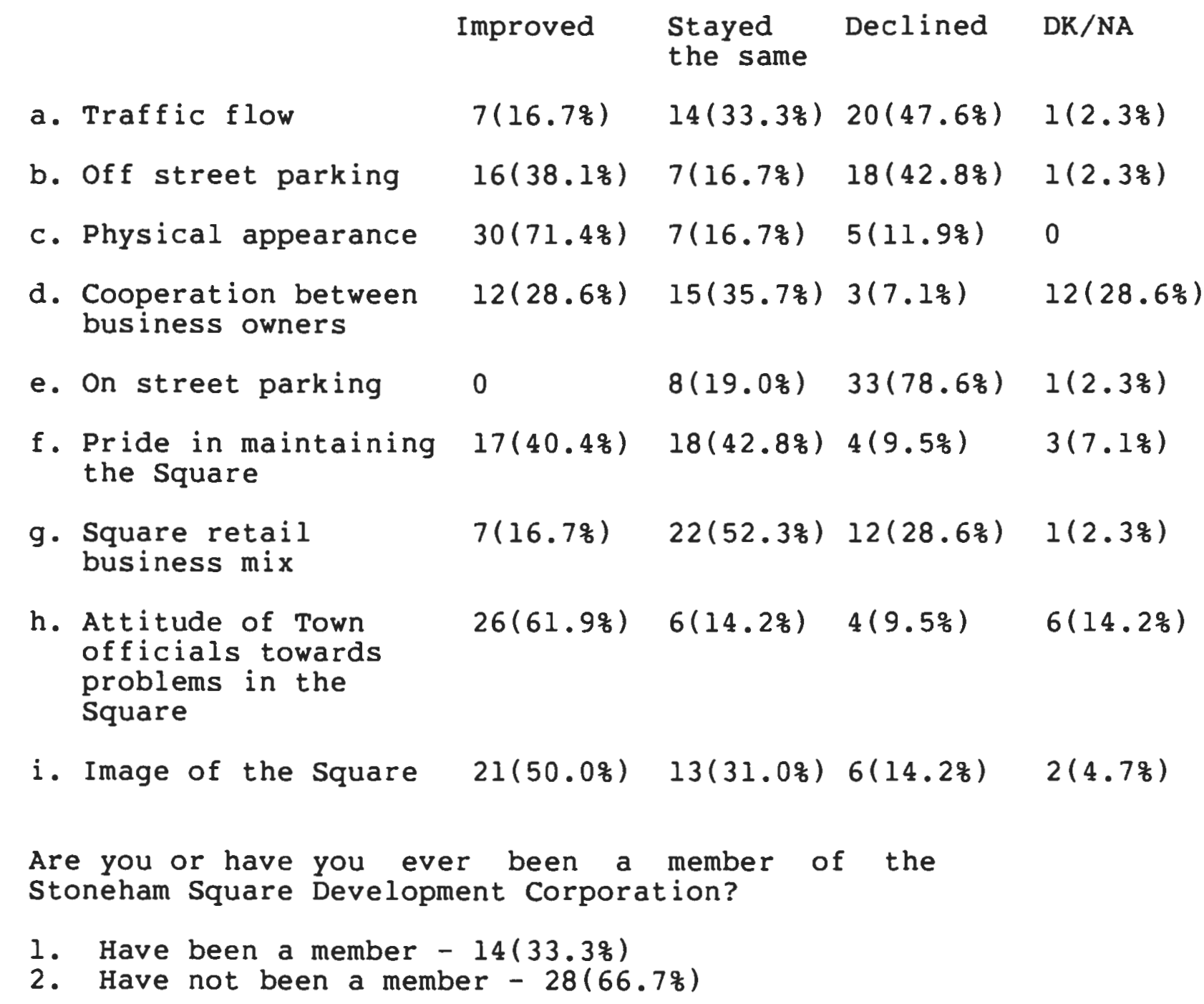




\section{I PROBLEM IDENTIFICATION AND EVALUATION}

10. Many believe Stoneham Square lacks the advantages that other downtown areas, such as neighboring Winchester, Melrose, and Wakefield have. If you had to select one of the following items as most lacking in Stoneham Square, which would it be? please select only one.

1. Lack of a large convenience retail store $5(11.98)$

2. The image of the Square - 5(11.9\%)

3. Poor retail mix - $12(28.6 \%)$

4. Traffic safety problems - $2(4.7 \%)$

5. Supply and availability of parking - 14(33.3\%)

6. Pedestrian safety problems - $1(2.3 \%)$

7. Building conditions - 3(7.1\%)

8. Another area, please specify NONE

9. DK/NA - 0

11. For the problem you selected in question 10, which one group, organization, or agency is best equipped to take the lead in handling this problem?

1. Stoneham Square Development Corporation $5(11.9 \%)$

2. Stoneham Board of Selectmen - 8(19.0\%)

3. Stoneham Planning Board - 0

4. Stoneham Community Development office $7(16.7 \%)$

5. The Chamber of Commerce - $4(9.5 \%)$

6. Property owners in the Square $-8(19.0 \%)$

7. Stoneham Department of Public Works - 1(2.3\%)

8. State Representatives or State Senator $2(4.78)$

9. $\mathrm{DK} / \mathrm{NA}-7(16.7 \%)$ 
12. The following is a list of many issues that have been raised that affect Stoneham Square today. For each one, please indicate whether you believe the problem or issue is a very serious one today, somewhat serious problem today, not too serious a problem, or not at all a problem today. First take:
Very
Somewhat
Not too
Not a
DK/NA
Serious Serious Serious Problem
a. Physical ap- pearance of buildings
$18(42.8 \%) 16(38.1 \%) \quad 7(16.7 \%) \quad 1(2.3 \%) \quad 0$
b. Traffic safety $14(33.3 \%) \quad 11(26.18) \quad 13(31.8 \%) \quad 4(9.5 \%) \quad 0$
c. Cooperation be- $8(19.08) \quad 18(42.8 \%) 6(14.28) \quad 1(2.3 q) \quad 9(21.48)$ tween business owners
d. Image of the $20(47.6 \%) 20(47.6 \%) 2(4.7 \%) \quad 0 \quad 0$ Square
e. On street $30(71.4 \%) \quad 10(23.8 \%) \quad 1(2.3 \%) \quad 1(2.3 \%) \quad 0$ parking
f. Pride in main- $19(45.28) \quad 18(42.8 \%) \quad 3(7.1 \%) \quad 1(2.3 \%) \quad 1(2.3 \%)$ taining the Square
g. Retail business $20(47.6 \%) \quad 17(40.4 \%) 5(11.9 \%) 00$ $\operatorname{mix}$
h. Attitude of $14(33.3 \%) \quad 11(26.1 \%) 7(16.78) \quad 5(11.98) 5(11.98)$ town of ficials towards problems in the Square
i. Off street $27(64.2 \%) \quad 10(23.8 \%) \quad 4(9.5 \%) \quad l(2.3 \%) \quad 0$ parking 
13. How good an investment do you think buying some commercial property in Stoneham Square would be at this time?

1. Excellent investment (Go to question 14) $4(9.5 \%)$

2. Good investment (Go to question 14) - 23(54.8\%)

3. Poor investment (Skip to question 15) $8(19.0 \%)$

4. Very bad investment (Skip to question 15) $4(9.5 \%)$

5. DK/NA (Skip to question 15) - 3(7.1\%)

14. Why do you feel investing in a property in the Square would be a good idea at this time? Which one of the following items best describes your reasoning?

1. Traffic conditions are improving - 0

2. Property values are increasing because of recent facade improvements - 3(11.1\%)

3. Property values are increasing in general $7(26.08)$

4. The possibility of bringing new business to the Square - 6(22.28)

5. Stoneham Square has unrealized potential $11(40.78)$

6. $\mathrm{DK} / \mathrm{NA}-0$

15. In May 1986, the Stoneham Chamber of Commerce sponsored an all-day workshop that brought together representatives of many interests to focus on problems in the square. Did you attend this workshop?

1. Yes (Skip to question 17) - 6(14.28)

2. No (Go to question 16) - 35(83.3\%)

3. DK/NA (Go to question 16) - $1(2.38$ )

16. Did you hear about this workshop or the results of its efforts?

1. Yes $-11(30.5 \%)$

2. No $-24(66.7 \%)$

3. $\mathrm{DK} / \mathrm{NA}-1(2.3 \%)$ 
17. Recently several buildings and facades have been and are being renovated in Stoneham Square. Were you aware that some of the funding for these projects was obtained by the Town of Stoneham through a Small Cities Grant from the State?

1. Yes, I was aware of the grant - 36(85.7\%)

2. No, I was not aware of the grant - 5(11.98)

3. DK/NA $-1(2.38)$

18. How significantly do you believe these facade renovations will improve the physical appearance of the Square? Will they make a considerable difference, some difference, not too much difference, or no difference at all in the appearance of Stoneham Square?

1. Considerable difference - 18(42.8\%)

2. Some difference - $20(47.68)$

3 . Not too much difference $-3(7.18)$

4. No difference at all-1(2.3\%)

5. $\mathrm{DK} / \mathrm{NA}-0$

19. As part of the State's Urban Systems Road Construction project, a large amount of critical on street parking has been lost in the square. To compensate, the State constructed a parking lot for 30 - 40 cars behind Gloucester Seafoods on Hill Street Court. How much improvement will this result in for the Square's parking problems? Will there be a great improvement in parking as a result of the new lot, some improvement, not much improvement, or no improvement?

1. Great improvement - $1(2.3 \%)$

2. Some improvement - $14(33.38)$

3. Not much improvement - 14(33.3\%)

4. No improvement at all - 13(31.0\%)

5. $\mathrm{DK} / \mathrm{NA}-\mathrm{O}$ 
III. GOAL CONSENSUS PROBLEM RESOLUTION

This section gives you an opportunity to provide input on what direction the town or its organizations can take to strengthen the downtown. Additional comments at the end of the survey are welcome.

20. The following is a listing of problems that are likely to affect stoneham square in the coming years. Which problems should be addressed as a highest priority by town officials or local organizations to make the square a better place for residents, shoppers, and merchants?

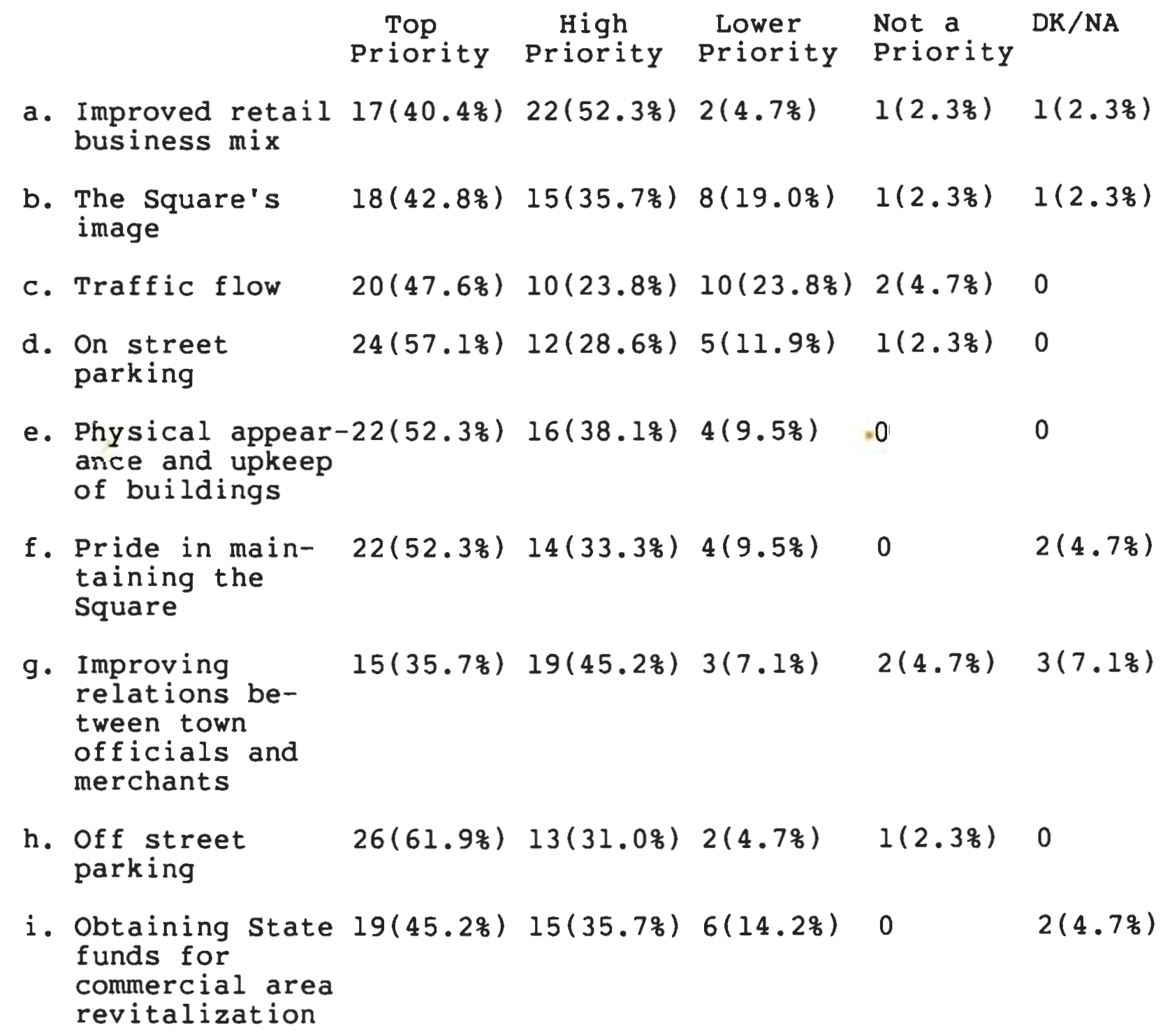


j. Promoting a $\quad 10(23.8 \%) \quad 14(33.38) \quad 12(28.68) \quad 2(4.78) \quad 4(9.5 \%)$ Square

identification

theme

k. Joint projects $12(28.6 \%) \quad 18(42.8 \%) \quad 7(16.7 \%) \quad 2(4.7 \%) \quad 3(7.1 \%)$

with the Stoneham

Square Development

Corp.

1. Stoneham Square 5(11.9\%) $11(26.1 \%) 20(47.6 \%) \quad 4(9.5 \%) \quad 2(4.7 \%)$ workshops or

seminars

m. A community $5(11.98) \quad 9(21.4 \%) \quad 17(40.4 \%) \quad 10(23.8 \%) \quad 1(2.3 \%)$ profile book

21. The State has approved downtown Stoneham for a Commercial Area Revitalization District (CARD). The CARD designation allows developers to work with town and state officials on financing for proposed downtown projects. Do you strongly favor, mildly favor, mildly oppose, or strongly oppose town officials working with developers in this way?

1. Strongly favor $-28(66.78)$

2. Mildly favor $-9(21.4 \%)$

3. Mildly oppose - $1(2.3 \%)$

4. Strongly oppose $-2(4.7 \%)$

5. DK/NA $-2(4.7 \%)$

22. The Community Development office is working on a community profile book that would colorfully highlight the town, it's Square, and available town services. Should funding for publishing and printing this book come from the town tax dollars, advertising by merchants, or by private donations?

1. Town tax dollars - 8(19.0\%)

2. Advertising by merchants - $11(26.1 \%)$

3. Private donation - 5(11.9\%)

4. Combination of all three sources - 17(40.4\%)

5. DK/NA - $1(2.3 \%)$ 
23. Considering the recent renovations to Stoneham Square, would a picture of Stoneham Square make a suitable cover for a book that residents could identify the community from?

1. Yes, would make a suitable cover - 24(57.1\%)

2. No, it would not make a suitable cover $15(35.7 \%)$

3. DK/NA $-3(7.1 \%)$

24. The Community Development office is looking at the installation of concrete planters, similar to those seen in Quincy Market or malls, to beautify the entire length of Route 28 and in particular, Stoneham square. From what you know, how responsive would merchants in the square be to purchasing and placing these planters in front of their stores as a cost of $\$ 300$ to $\$ 500$ ? Would they be very favorable to this idea, somewhat favorable, not too favorable, or not at all favorable to purchasing planters and placing them in front of their stores?

1. Very favorable - 3(7.1\%)

2. Somewhat favorable - $10(23.8 \%)$

3. Not too favorable - 22(52.38)

4. Very unfavorable - $1(2.38)$

5. DK/NA - $6(14.28)$

25. How high a priority should a beatification project of this type be for Stoneham square? Should it be a top priority for Stoneham Square, an important priority, a minor priority, or not a priority at all for the Square?

1. Top priority - $9(21.4 \%)$

2. Important priority - 17(40.4\%)

3. Minor priority - 14(33.3\%)

4. Not a priority $-2(4.7 \%)$

5. $\mathrm{DK} / \mathrm{NA}-0$ 
26. A recent study by Connery Associates of Winchester showed the need for a large off street parking facility to accommodate 150 cars. A proposal of this type involves a land taking at fair market value. How important, in your opinion, is such a development proposal to the future of Stoneham Square? Is it very important, somewhat important, not too important, or not important at all to the future of Stoneham Square?

1. Very important - 32(76.2\%)

2. Somewhat important $-8(19.0 \%)$

3. Not too important - 0

4. Not important at all - 2(4.7\%)

5. DK/NA - 0

27. A proposed parking facility would cost in the vicinity of $\$ 1.5$ million to $\$ 2$ million for land acquisition and construction. The State off Street Parking Program could pay for $75 \%$ of this cost with the remaining $25 \%$ to be picked up by the town. Should property owners and merchants in the square be asked to make financial contributions to help the town pay for $25 \%$ of the cost?

1. Yes, the merchants and owners should help pay for the cost - $12(28.6 \%)$

2. No, the town should have the sole responsibility for this funding - $(27(64.28)$

3. DK/NA $-3(7.1 \%)$

28. Should a parking fee be paid by all-day parkers?

1. Yes, a fee should be paid (Go to next question) - $34(81.0 \%)$

2. No, no fee necessary (Skip to question 30) $8(19.0 \%)$

29. How much should the fee be per day?

1. Fifty cents $-8(23.5 \%)$

2. One dollar - 14(41.0\%)

3. One dollar and fifty cents - 0

4. Two dollars $-9(26.58)$

5. DK/NA - 3(8.8\%) 
30. To conclude, which of the following issues do you consider to be most crucial to the future of Stoneham Square in the coming years? Please feel free to select more than one item.

1. Improvement of physical appearance of the Square - 25(59.5\%)

2. Improved retail mix - 25(59.5\%)

3. The image of the Square - 16(38.18)

4. On street parking - 25(59.5\%)

5. A downtown beautification program - 15(35.7\%)

6. A community profile book - $2(4.7 \%)$

7. Lack of off street parking - 29(69.0\%)

8. Obtaining state funds for commercial area revitalization - $18(42.8 \%)$

9. Improving traffic flow - 14(33.3\%)

10. Organizing and promoting a marketing theme for businesses in the Square - 10(23.8\%)

11. Another issue (please indicate):

Education of voters/community, Need for marketing services in the Square, Cooperation between all parties, Lack of community pride, Litter problem

Thank you for taking the time and effort needed to complete this survey! Please return it to the Community Development Coordinator, Lou Mercuri, at Stoneham Town Hall, 35 Central Street, Stoneham, 02180.

\section{ADDITIONAL COMMENTS ARE WELCOME!!}

- Parking is the crucial issue

- Formation of a historic district

- Merchants should contribute to cost of garage

- Community profile book important

- Planters should cost no more than $\$ 300$

- Improve the retail mix

- Input from citizens and merchants is the key

- Form a joint Stoneham Square Revitalization Committee

- Need a parking ordinance to make sure additional square footage of parking is provided for new development/business

- Teach students at high school about the upgrading of the town center 


\section{SELECTED BIBLIOGRAPHY}

Alwin, Duane F., ed. Survey Design and Analysis: Current Issues. Beverly Hills: Sage Publications, 1978.

Bendavid-Val, Avrom.

Local Economic Development Planning:

From Goals to Projects. Chicago: American Planning Association, [1980].

A concise description of the process of community and economic development planning from data collection to performance evaluation.

Bens, Charles K., "Strategies for Implementing Performance Measurement," MIS Report 18 (November 1986).

A summary of how to measure the performance component of implemented objectives.

Berk, Emanuel. Downtown Improvement Manual. Chicago: American Planning Association, 1981.

An in-depth examination of downtown improvement issues and their resolution. Includes a section on opinion surveys with sample questionnaires.

Clary, Bruce, and Perlman, Lee. "A Framework for Citizen Participation: Portland's office of Neighborhood Associations," MIS Report 18 (September 1986).

Creighton, James L., The Public Involvement Manual. Cambridge: Abt Books, 1981.

Provides information on the validity of surveys in different contexts.

Favero, Philip. Local Economic Development: A

Strategic Approach. Washington: International

City Management Association, 1984. 
Frey, James H., Survey Research by Telephone. Beverly Hills: Sage Publicaitons, 1984 .

Hechenbleikner, Peter I., "Citizen Surveys: A Tool of the Trade," MIS Report 16 (October 1984): 9-14.

Peacock, Harry R., "Determining Community Needs With Community Surveys," MIS Report 16 (October 1984): 15-21.

Smith, Frank J., and Hester, Randolph T. Jr., Community Goal Setting. Pennsylvania: Hutchinson Ross Publishing Company, 1982.

An in-depth study of goals as part of the formulation of policy making.

Sudman, Seymour. Applied Sampling. New York: Academic Press, 1976.

Webb, Kenneth, and Hatry, Harry P., Obtaining Citizen Feedback: The Application of Citizen Surveys to Local Governments. Washington D. C.: The Urban Institute, 1973.

Although somewhat dated, an in-depth guide to conducting several different types of surveys.

Weiss, Carol H. and Hatry, Harry P., "Basics In Conducting Citizen Surveys," MIS Report 16

(October 1984): 1-8. 